\title{
Activity-Dependent Regulation of NMDAR1 Immunoreactivity in the Developing Visual Cortex
}

\author{
Susan M. Catalano, Catherine K. Chang, and Carla J. Shatz \\ Howard Hughes Medical Institute and Department of Molecular and Cell Biology, University of California, \\ Berkeley, California 94720
}

\begin{abstract}
NMDA receptors have been implicated in activity-dependent synaptic plasticity in the developing visual cortex. We examined the distribution of immunocytochemically detectable NMDAR1 in visual cortex of cats and ferrets from late embryonic ages to adulthood. Cortical neurons are initially highly immunostained. This level declines gradually over development, with the notable exception of cortical layers $2 / 3$, where levels of NMDAR1 immunostaining remain high into adulthood. Within layer 4 , the decline in NMDAR1 immunostaining to adult levels coincides with the completion of ocular dominance column formation and the end of the critical period for layer 4 . To determine whether NMDAR1 immunoreactivity is regulated by retinal activity, animals were dark-reared or retinal activity was completely blocked in one eye with tetrodotoxin (TTX). Dark-rearing does not cause detectable changes in NMDAR1 immunoreactivity. However, 2 weeks of monocular TTX administration decreases
\end{abstract}

NMDAR1 immunoreactivity in layer 4 of the columns of the blocked eye. Thus, high levels of NMDAR1 immunostaining within the visual cortex are temporally correlated with ocular dominance column formation and developmental plasticity; the persistence of staining in layers $2 / 3$ also correlates with the physiological plasticity present in these layers in the adult. In addition, visual experience is not required for the developmental changes in the laminar pattern of NMDAR1 levels, but the presence of high levels of NMDAR 1 in layer 4 during the critical period does require retinal activity. These observations are consistent with a central role for NMDA receptors in promoting and ultimately limiting synaptic rearrangements in the developing neocortex.

Key words: NMDAR1; activity-dependent; visual cortex; development; critical period; plasticity
Neural activity is required for pattern formation and synaptic plasticity in neocortex (Katz and Shatz, 1996). During the segregation of geniculocortical axons to form ocular dominance columns in development, monocular deprivation causes a functional and anatomical expansion of the open eye's cortical territory (Hubel et al., 1977; Shatz and Stryker, 1978; Stryker and Harris, 1986; Antonini and Stryker, 1993a), whereas eliminating all retinal activity in both eyes prevents column formation (Stryker and Harris, 1986). The formation of highly specific horizontal connections between orientation-specific domains in layers 2/3 also requires visual experience (Callaway and Katz, 1991; Ruthazer and Stryker, 1996).

NMDA receptors are thought to be involved in mediating activity-dependent synaptic plasticity in the developing CNS (Fox and Daw, 1993; Bear, 1996). The physiological shift toward the open eye that occurs in monocularly deprived animals can be blocked by cortical APV infusion (Kleinschmidt et al., 1987; Gu et al., 1989; Bear et al., 1990). The shrinkage of LGN cells related to the deprived eye is also blocked by APV infusion (Bear and Colman, 1990). In frog optic tectum, infusion of APV initiates desegregation of eye-specific stripes (Cline and ConstantinePaton, 1990). The segregation of on-off sublaminae in ferret LGN is prevented by APV infusion (Hahm et al., 1991). APV

Received June 23, 1997; revised Aug. 13, 1997; accepted Aug. 20, 1997.

This research was supported by National Institutes of Health Grant R32 EY02858 to C.J.S. and National Research Service Award EY06491 to S.M.C. C.J.S. is an investigator of the Howard Hughes Medical Institute. We thank Denise Escontrias and Alma Raymond for invaluable assistance with animal husbandry and surgeries.

Correspondence should be addressed to Dr. Susan M. Catalano, Life Sciences Addition 221, University of California, Berkeley, CA 94720.

Copyright (C) 1997 Society for Neuroscience $0270-6474 / 97 / 178376-15 \$ 05.00 / 0$ infusion into neonatal rat somatosensory cortex alters both somatotopic rearrangements resulting from peripheral manipulations and physiological organization within layer 4 (Schlaggar et al., 1993; Fox et al., 1996). Finally, mice lacking the NMDAR1 subunit fail to exhibit the whisker-related barreloid pattern normally present in the trigeminal brainstem nuclei at birth (Li et al., 1994; Iwasato et al., 1997). These observations suggest that NMDA receptors play a crucial role in anatomical and physiological activity-dependent pattern formation and plasticity during development.

Physiological evidence suggests that there is a developmental regulation of NMDA receptors coincident with periods of cortical plasticity (such as ocular dominance column formation) and that this regulation itself may be activity-dependent. In cat visual cortex, the percentage of the visual response of individual neurons that is NMDAR-mediated decreases between 3 and 6 weeks of age; dark-rearing prevents this decrease (Fox et al., 1989, 1991, 1992). One possible mechanism that might underlie the decrease in NMDA-mediated responses is a change in NMDA receptor kinetics. For instance, in rat visual cortex, the duration of the NMDA-mediated EPSC decreases during development, and dark-rearing prevents this decrease (Carmignoto and Vicini, 1992). This decrease could be caused by a shift in NMDA receptor subunit expression (Sheng et al., 1994; Flint et al., 1997). Another possibility, not mutually exclusive, is that the levels of NMDA receptors themselves change during development in association with periods of cortical plasticity. A number of recent studies suggest that NMDA receptors are regulated at the posttranscriptional rather than the mRNA level (Sucher et al., 1993; Gazzaley et al., 1996). To investigate these possibilities, we ex- 
amined the distribution of NMDA receptors during development using an antibody directed against the R1 subunit. This subunit is essential for NMDA receptor function (Moriyoshi et al., 1991; Monyer et al., 1992; Nakanishi, 1992). We also examined whether NMDAR1 levels are regulated in an activity-dependent manner by raising animals in the dark or blocking activity in one eye with tetrodotoxin (TTX) injections.

\section{MATERIALS AND METHODS}

Immunocytochemistry. A total of 27 normal ferrets ranging in age from embryonic day (E) 30 to adulthood and 32 normal cats from E42 through adult were studied. Additional cats were examined after dark-rearing $(n=7)$, dark-rearing followed by brief reexposure to light $(n=3)$, or monocular injections of TTX $(n=3)$. One monoclonal antibody (clone 54.1; PharMingen, San Diego, CA) and three polyclonal antibodies (Chemicon, Temecula, CA; gift of Dr. M. Sheng, Howard Hughes Medical Institute Massachusetts General Hospital; gift of Dr. T. Dawson, Johns Hopkins University School of Medicine) raised against different epitopes in the rat sequence of the NMDAR1 subunit were assessed for their ability to stain cat and ferret tissue and for specificity of staining. Antibody staining of Western blots (see below) and tissue sections of cat, ferret, and NMDAR1 knock-out mouse brain were examined. Only the monoclonal antibody from PharMingen specifically recognized NMDAR1 in cat and ferret tissue. This antibody was raised against a fusion protein corresponding to the extracellular loop between transmembrane domains III and IV (Brose et al., 1994) of NMDAR1, a region that is $100 \%$ homologous between mouse and human. This high degree of conservation suggests that the carnivore and mustelid sequences are likely to be similar in this region and probably underlies the successful staining of cat and ferret tissue, as described in Results.

Fetal ages were determined by timed breedings as described previously (Luskin and Shatz, 1985a); gestation is $\sim 42 \mathrm{~d}$ in ferret and $65 \mathrm{~d}$ in cat Timed pregnant ferrets were obtained from Marshall Farms (North Rose, NY). Fetuses were anesthetized transplacentally through maternal anesthesia with an isofluorane $/ \mathrm{O}_{2}$ mixture. Postnatal animals were anesthetized deeply with sodium pentobarbitol $(50 \mathrm{mg} / \mathrm{kg})$ injected intraperitoneally. Animals were perfused transcardially with $0.1 \mathrm{M}$ sodium phosphate buffer followed by fresh $4 \%$ paraformaldehyde in the same buffer. Brains were dissected and cryoprotected in $30 \%$ sucrose in $0.1 \mathrm{M}$ sodium phosphate buffer overnight at $4^{\circ} \mathrm{C}$.

Frozen sections were cut at $30-40 \mu \mathrm{m}$ on a sliding microtome, and free-floating sections were washed with PBS $(0.1 \mathrm{M}$ sodium phosphate buffer, $0.9 \% \mathrm{NaCl}, \mathrm{pH} 7.4$ ), blocked in normal horse serum (NHS) (Vector, Burlingame, CA) at a concentration of 5\% in PBS for $1 \mathrm{hr}$, and then incubated overnight in primary antibody (1:500 or 1:50 in 1\% NHS) (PharMingen). All reactions were performed at room temperature; primary, secondary, and avidin-biotin incubations were performed with mild agitation, and washes were $3 \times 10 \mathrm{~min}$ in PBS. Sections were incubated with biotin-coupled secondary antibody and then avidin-HRP conjugate and reacted with $\mathrm{DAB}$ according to the Vector $\mathrm{ABC}$ kit protocol (Vector). All sections were developed for the same time in DAB. The reaction was stopped by washing $3 \times 3 \mathrm{~min}$ in PBS. Sections were mounted onto slides from a gelatin solution, dehydrated with alcohol, and coverslipped with Permount.

Controls included incubation of the sections (1) omitting primary antibody, (2) substituting generic mouse IgG protein at an equivalent concentration to the primary antibody, and (3) adsorption of the primary antibody with the fusion protein immunogen (Kopke et al., 1993). We would like to thank Dr. A. Kopke (Department of Molecular Neuroendocrinology, Max Planck Institute for Experimental Medicine, Gottingen, Germany) for his generous gift of fusion protein.

Western analysis. Synaptic plasma membranes of rat, cat, and ferret neocortex and cell membranes of ferret liver were prepared (Brose et al., 1990), and constituent proteins were resolved by 9\% SDS-PAGE gels under reducing conditions (5 $\mu \mathrm{g}$ total protein/lane). Proteins were immobilized on nitrocellulose membranes (Hybond ECL), and blots were blocked for 1 $\mathrm{hr}$ at room temperature in PBS with 5\% nonfat dry milk, 5\% normal donkey serum, and $0.1 \%$ Tween 20 and then incubated with primary antibody at a concentration of 1:500 in PBS with 5\% nonfat dry milk, $0.1 \%$ Tween 20, and 3\% bovine serum albumin (BSA) (Sigma, St. Louis, MO) overnight at $4^{\circ} \mathrm{C}$. Blots were then washed $4 \times 15 \mathrm{~min}$ in PBS with $0.1 \%$ Tween 20 and then incubated in secondary antibody [HRP-conjugated donkey anti-mouse 1:8000 (Jackson ImmunoResearch, West Grove, PA)] in PBS with $0.1 \%$ Tween $20,0.1 \%$ BSA, and $5 \%$ NHS, and then washed $1 \times 5$ min in Tris-buffered saline (TBS) $(0.1 \mathrm{~m}$ Tris with $0.9 \% \mathrm{NaCl}, \mathrm{pH}$ 7.4), $2 \times 5$ min in TBS with $1 \%$ Triton $\mathrm{X}-100,1 \%$ SDS, $0.5 \%$ deoxycholic acid in TBS, and then $2 \times 5$ min in PBS with $0.1 \%$ Tween 20 . Antibody was then visualized by enhanced chemiluminescence (Amersham, Arlington Heights, IL). As a control, the primary antibody was preadsorbed with NMDAR1 fusion protein (Kopke et al., 1993).

Dark-rearing. Animals housed in conventional cat racks $(2$ feet $\times 4$ feet) with their mothers were placed in a completely light-tight room in total darkness within 3-4 d of birth (1 week before eye opening). A total of seven cats were raised in complete darkness until they were killed (to $\mathrm{P} 15, n=1 ; \mathrm{P} 28, n=1 ; \mathrm{P} 34, n=1 ; \mathrm{P} 53, n=2 ; \mathrm{P} 103, n=2)$. We also studied two animals that were raised in the dark until P53 and then reexposed to light (one for $4 \mathrm{~d}$, the other for $10 \mathrm{~d}$ ) as well as one animal raised in the dark until P103 and then reexposed to light for $10 \mathrm{~d}$. A contact-activated electric switch on the entrance to the dark-rearing room ensured that no accidental exposure to light could occur. Additionally, light within the room was monitored with photocells wired to a recording machine (Angus Electronics, Indianapolis, IN) that gave a continuous readout; no light was detected in the dark-rearing room for the duration of this study. No changes in configuration of cage items such as food bowls and perches were made once the animals were placed in the dark. An auto-reverse tape player provided an enriched auditory environment for 8-12 hr per day. Mothers were permitted to exercise in a lighted anteroom each day for at least $15 \mathrm{~min}$. Animal care and feeding were performed by visually monitoring animals using an infrared headset. A registered veterinary technician checked the health of the kittens each day. Kitten weight gain was monitored every third day for the first three weeks of life and then weekly until the animals were removed from the colony. No clinical health problems were observed in any of the animals raised in this environment. Animals reintroduced into the light in identically configured cages did not show signs of distress.

TTX eye injections. $\mathrm{P} 40$ kittens were anesthetized with isofluorane and injected monocularly with either a sterile solution of $3 \mathrm{~mm}$ TTX (Calbiochem, La Jolla, CA) in $18.6 \mathrm{~mm}$ citric acid-sodium citrate buffer, $\mathrm{pH}$ $4.8(n=2)$, or vehicle alone $(n=1)$. Injections were continued every other day for 2 weeks (dose $4-5 \mu \mathrm{l}$ at P40, increasing gradually to 7.5-9 $\mu \mathrm{l}$ by 2 weeks). The absence of direct and consensual pupillary response to light was taken as an indication of effective TTX blockade of visual responses (Stryker and Harris, 1986) and was monitored hourly for the first $3 \mathrm{hr}$ after injection and at least three times a day thereafter.

Image analysis. Digital images of immunostained tissue sections were acquired using a VE1000 video camera (Dage-MTI, Michigan City, IN), allowing immunostaining intensity to be quantified in units of pixel gray scale value ( 8 bit). We measured the periodic variation in NMDAR1 immunostaining intensity in layer 4 in the monocularly TTX-injected, citrate-injected, and normal age-matched animals in a direction parallel to the cortical surface (see Fig. 9). A region within layer 4 measuring 2.5 $\mathrm{mm}$ long by $0.23 \mathrm{~mm}$ thick (long axis parallel to the pia) was sampled. This region covered almost all of the thickness of layer 4, as determined by inspection of adjacent sections counterstained with cresyl violet. The average immunostaining intensity was averaged over each line of pixels extending vertically through layer 4 , and these average values were plotted as a function of distance along the length of layer 4 parallel to the pia (National Institutes of Health Image). This plot was smoothed by averaging each value with its four nearest neighbors, and the resulting values are presented in Figure 9. This method was designed to be similar to the analysis used by LeVay et al. (1978) to determine the degree of ocular dominance column segregation in layer 4 during development.

To compare relative levels of immunostaining across ages and different experimental conditions (see Fig. 10), the ratio of the average staining in layers $2 / 3$ to the average staining in layer 4 for a given animal was obtained in the following manner. The average immunostaining intensity in layers $2 / 3$ was calculated from pixel gray values in a region of the digitized images measuring $0.25 \mathrm{~mm}$ in length (tangential to the pia) by $0.20 \mathrm{~mm}$ through the vertical dimension of cortex. This region was entirely confined to layers $2 / 3$ by comparison with adjacent Nissl-stained sections. Then the average immunostaining intensity in layer 4 was calculated from an identically sized sample taken from a region of layer 4 that was located immediately underneath the layers $2 / 3$ sample in the same tissue section. The ratio of this pair of average staining values was then obtained. This procedure was repeated for 16 samples (eight pairs of samples), equivalent to $1.6 \mathrm{~mm}^{2}$ of cortical area across tissue sections from a given animal. The ratio values from a given animal were then averaged and plotted in Figure 10. In the case of the TTX-treated 
animals, the sample areas were taken from regions of maximal and minimal immunostaining in layer 4 as determined visually.

\section{RESULTS}

NMDAR1 subunit protein was detected immunocytochemically in the visual cortex of cats and ferrets. We examined the period of development beginning at a time in fetal life before LGN axons have grown into the visual cortical plate (E30 ferret, E42 cat) (Ghosh and Shatz, 1992) through the period of ocular dominance column formation [cat P21-42 (LeVay et al., 1978) and ferret P36-49 (Ruthazer et al., 1995; E. Finney and C.J. Shatz, unpublished observations)], through the critical period when abnormal experience can alter geniculocortical connectivity within layer 4, to adulthood. We then compared the immunocytochemical localization of NMDAR1 of normal cats to that of age-matched animals raised in the dark from birth and animals in which retinal activity had been blocked for 2 weeks by monocular injections of TTX. Finally, we compared the immunocytochemical localization of NMDAR1 in developing visual cortex with that of other nonvisual cortical areas.

\section{Antibody specificity}

Western analysis indicates that the monoclonal anti-NMDAR1 antibody (PharMingen 54.1) recognizes a band of the same molecular weight as NMDAR1 $\left(M_{\mathrm{r}} \sim 117 \mathrm{kDa}\right)$ in synaptic plasma membranes prepared from rat, cat, and ferret brains (Fig. 1A1). This band is absent in membranes prepared from ferret liver (Fig. $1 A 1)$ or when the primary antibody is preadsorbed with the NMDAR1 fusion protein (Fig. 1A2) or omitted (Fig. 1A3). To examine the specificity of antibody staining, tissue sections stained with anti-NMDAR1 (Fig. 1B1) were compared with sections incubated in either primary antibody preadsorbed with the NMDAR1 fusion protein (Fig. 1B2) or nonimmune mouse IgG (Fig. 1B3). When the primary antibody is preadsorbed to the fusion protein against which it was raised, cellular staining is absent (Fig. 1B2), indicating that the NMDAR1 epitope on the fusion protein can compete for binding of the primary antibody in tissue sections. In sections incubated with mouse IgG (Fig. 1B3), cellular staining is also absent. These two immunocytochemistry controls indicate that the immunostaining observed in tissue sections with the anti-NMDAR1 antibody is not caused by nonspecific binding of either the primary or secondary antibody. Taken together, this evidence strongly suggests that the antiNMDAR1 antibody selectively recognizes the R1 subunit of the NMDA receptor.

\section{Developmental changes in pattern of protein expression}

In ferret visual cortex, immunocytochemically detectable NMDAR1 is located in specific cellular compartments in the developing cerebral wall (Fig. 2). At 35 d of gestation (E35; birth is on E41-42), fibers within the marginal zone (future layer 1) and the intermediate zone (future white matter) are immunostained (Fig. 2A). There was no detectable immunostaining of migrating neurons in the intermediate zone; however, the dense cortical plate, which contains neurons that are immediately postmigratory, is immunopositive. Subplate neurons, which are among the earliest cells of the cortex to be generated and thus to differentiate, are the first neurons of the cortex to exhibit intense NMDAR1 immunoreactivity (Fig. $2 A, B$ ). By P3 (Fig. 2C), neurons within layer 6 have begun to differentiate from the dense cortical plate and are as intensely immunostained as the subplate neurons. The dense cortical plate (which at this age contains

\section{A. Western Blot Controls}

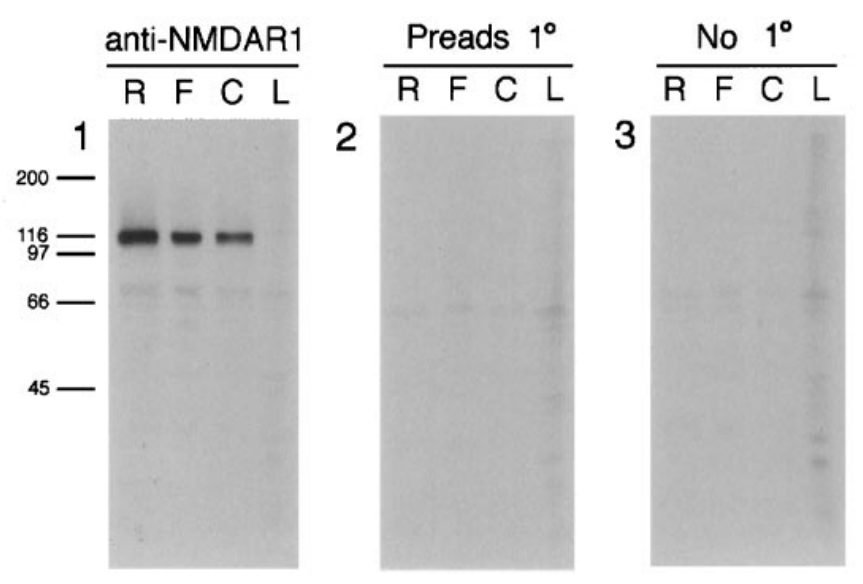

B. Immunocytochemistry Controls

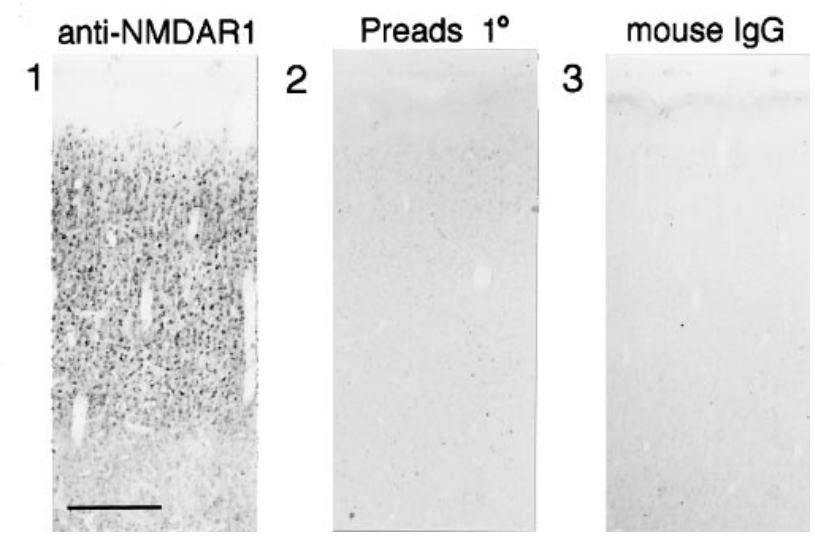

Figure 1. A, Western blots show that the monoclonal antibody recognizes a band of the same molecular weight as NMDAR1. $A 1$, Staining of rat $(R)$, ferret $(F)$, and cat $(C)$ synaptic plasma membranes and ferret liver membranes $(L)$ with the primary anti-NMDAR1 antibody yields a prominent band at $M_{\mathrm{r}} \sim 117 \mathrm{kDa}$. This band is no longer stained when the primary antibody is preadsorbed to its fusion protein immunogen $(A 2)$, or omitted (A3). B, Controls for the specificity of NMDAR1 antibody immunostaining on tissue sections. Cellular staining is intense in sections that have been incubated in primary antibody (B1); however, preadsorbtion of the primary antibody with the fusion protein that it was raised against $(B 2)$ or substitution of the primary antibody with generic IgG protein from the same species as the primary (mouse $\mathrm{IgG})(B 3)$ protein results in the near-absence of cellular staining. Scale bar (B1-3): $300 \mu \mathrm{m}$.

neurons belonging to future layers 5 and 4) (Jackson et al., 1989) itself is also immunoreactive. By P20, (Fig. 2D) all of the cortical layers have differentiated. Immunoreactivity within layers 4 and 6 has declined, but that of layers $2 / 3$ and 5 remains relatively intense. By P49 (Fig. 2E), NMDAR1 immunoreactivity in layer 5 has declined and is similar to that of layer 6 . In contrast, immunostaining in layer 4 has increased and is similar to that of layers 2/3. Layer 1 is no longer immunoreactive. By P84 (Fig. $2 F$ ) and in adulthood (Fig. $2 G$ ), immunostaining in layer 4 has declined and is now similar to that seen in the lower cortical layers 5 and 6 . Immunoreactivity remains relatively intense in the upper cortical layers $2 / 3$.

From these observations, a general pattern of developmental regulation of immunocytochemically detectable NMDAR1 in ferret visual cortex can be discerned. Neurons exhibit intense 


\section{FERRET VISUAL CORTEX}

\section{E 35}

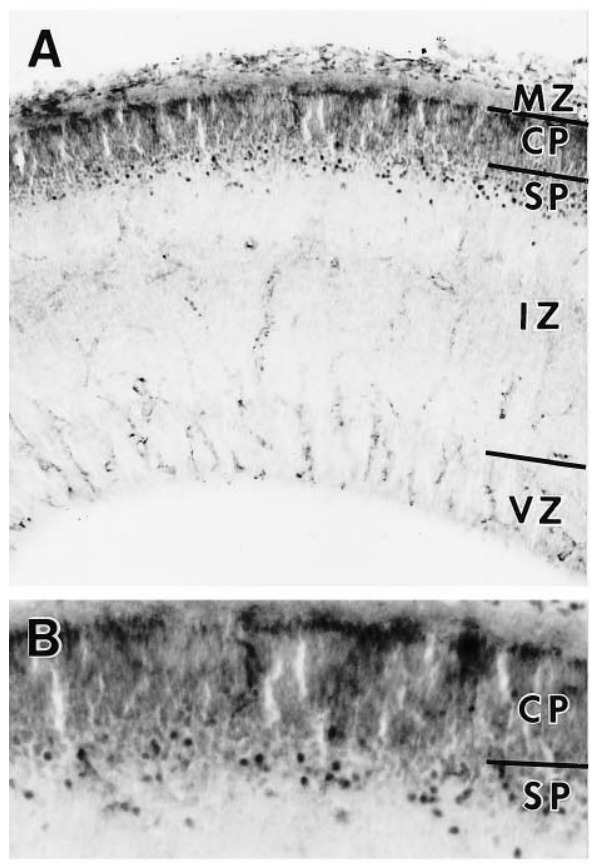

P 49

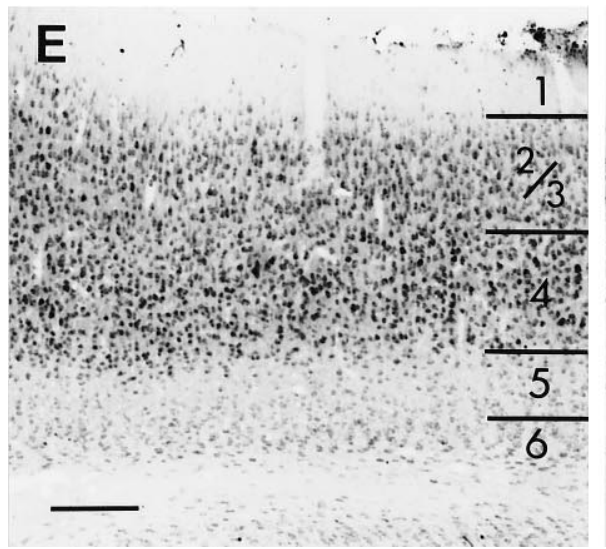

P 3

C

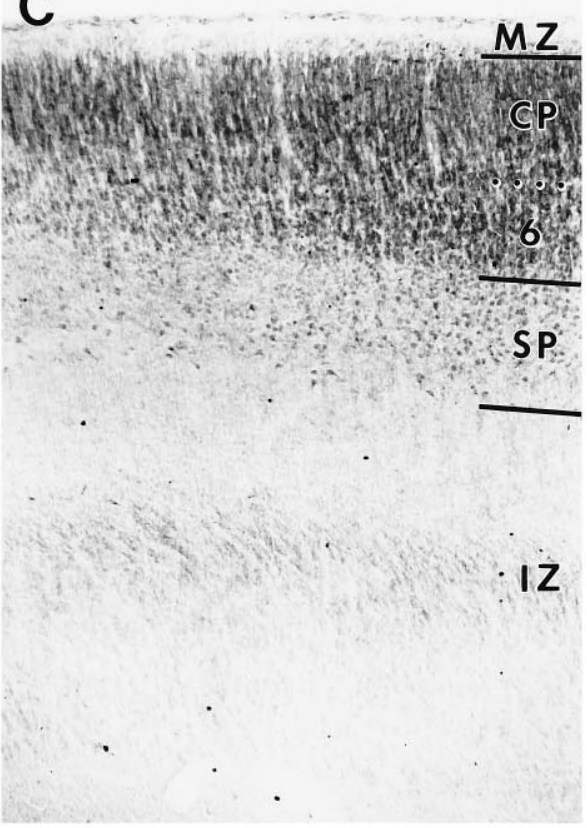

P 84

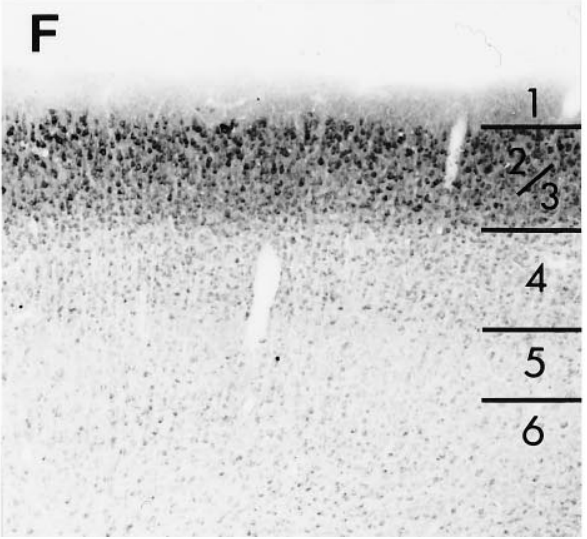

P 20

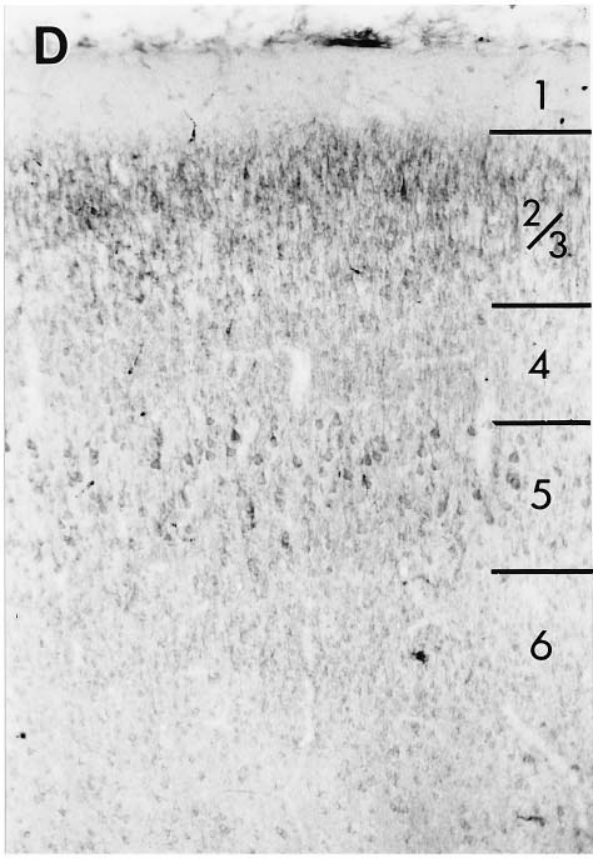

Adult

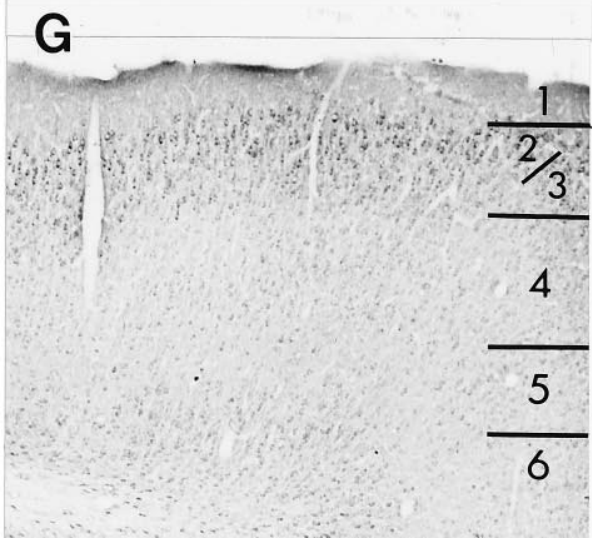

Figure 2. The pattern of NMDAR1 immunoreactivity during the development of the ferret visual cortex at $E 35(A, B), P 3(C), P 20(D), P 49(E), P 84$ $(F)$, and Adult $(G)$. Laminar boundaries are indicated by horizontal bars. $C P$, Cortical plate; $S P$, subplate; $I Z$, intermediate zone; $V Z$, ventricular zone; $1-6$, cortical layers 1-6. Scale bar (bottom left in $E$ ): $A, C, D, 110 \mu \mathrm{m} ; B, 55 \mu \mathrm{m} ; E-G, 200 \mu \mathrm{m}$.

immunoreactivity shortly after becoming postmigratory, and this level of immunoreactivity declines gradually over development. The exceptions to this are layers $2 / 3$, which remain intensely immunoreactive throughout development into adulthood, and layer 4, which exhibits a more complex pattern of staining: after the initial decline in immunoreactivity, there is a subsequent increase in the level of NMDAR1 immunostaining in layer 4, followed by a second period of decline in immunoreactivity.

Similar changes in the laminar-specific patterns of NMDAR1 immunostaining are seen in the developing cat visual cortex (Fig. 3). At E42, fibers within the intermediate zone and marginal zone are immunopositive (Fig. $3 A$ ). The dense cortical plate and sub- plate cells are intensely immunoreactive. By birth ( $\mathrm{P} 0$, equivalent to E65) (Fig. 3B), differentiated layer 6 is immunostained as intensely as the dense cortical plate and subplate neurons. By P28 (Fig. 3C), NMDAR1 immunoreactivity in layers 4 and 6 has declined, whereas layers $2 / 3$ and 5 remain intensely immunostained. At P34 (data not shown) and P40, immunoreactivity in layer 5 has declined and is similar in intensity to that in layer 6 (Fig. 3D). Immunostaining in layer 4 has increased, is now similar to that of layers $2 / 3$, and is uniform throughout both of these layers (but see Murphy et al., 1996). By P108, immunoreactivity in layers $2 / 3$ remains intense (Fig. $3 E$ ). NMDAR1 immunostaining in layer 4 has declined and is now similar to that of layer 6 . In 


\section{CAT VISUAL CORTEX}

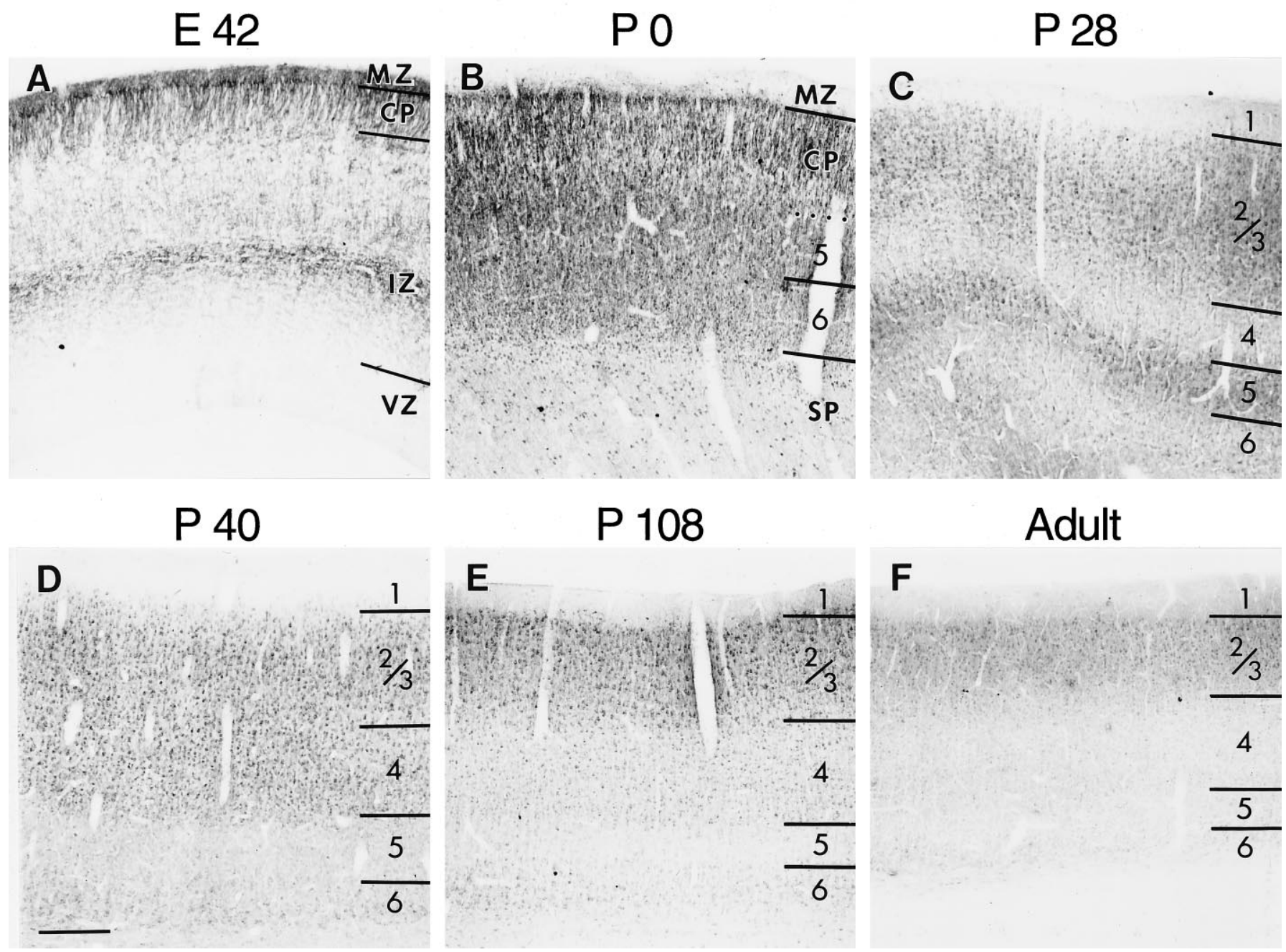

Figure 3. NMDAR1 immunoreactivity in the developing cat visual cortex at $E 42(A), P 0(B), P 28(C), P 40(D), P 108(E)$, and $A d u l t(F)$. Note the progressive loss of staining from the deeper cortical layers at older ages. See Figure 2 for abbreviations. Scale bar $($ bottom left in $D): A$, $C, 120 \mu \mathrm{m} ; B$, $230 \mu \mathrm{m} ; D, E, F, 300 \mu \mathrm{m}$.

adulthood, only layers $2 / 3$ remain intensely immunoreactive (Fig. $3 F)$. A higher magnification view of the border between layers 4 and 5 in cat visual cortex at P40 (Fig. 4A) highlights several key features of NMDAR1 immunoreactivity. Cells in layer 4 are more intensely immunostained than those in layer 5. Both pyramidal and stellate cell types are immunoreactive, with the cell body and proximal dendrites being the most intensely immunostained. Glial cell staining is not observed at any age. The neuropil is also diffusely immunoreactive. This staining is specific, as can be appreciated by noting the precipitous decline in diffuse staining in layer 5 (Fig. $4 A$ ) and also in the virtual absence of staining in cortical layer 1 as compared with layers $2 / 3$ (Fig. $4 B$ ). At least some of this neuropil staining is also likely to be attributable to dendritic immunoreactivity (arrows in Fig. 4A,B), which is as intense as that of the cell bodies. We consider it highly unlikely that the decline in immunostaining in layers $4-6$ is caused by myelination, because layers $2 / 3$ horizontal connections are also myelinated and immunoreactivity within this layer remains high into adulthood. Moreover, a good deal of the change in immunostaining is caused by the loss of somatic staining, which obviously cannot be attributed to myelination-based problems in antibody accessibility.

Levels of immunocytochemically detectable NMDAR1 change in development with a laminar-specific time course. However, the transient increase in layer 4 is noteworthy in that it coincides with major developmental events in cat visual cortex. After the initial decrease in layer 4 immunostaining, which occurs between $\mathrm{P} 0$ and P15 in the cat, NMDAR1 immunoreactivity is subsequently increased in layer 4 , and this increase occurs during the period of ocular dominance column formation (P21-42) (LeVay et al., 1978). NMDAR1 immunoreactivity then declines to adult-like levels by P76, which is past the age when abnormal visual experience can lead to changes in the anatomical pattern of ocular dominance columns within layer 4 (Mower et al., 1985). After this age, anatomical rearrangements of thalamocortical axons can no longer be induced by alterations of activity (such as lid suture). In contrast to layer 4 , recent evidence suggests that anatomical rearrangements can occur in layers $2 / 3$ into adulthood in response 

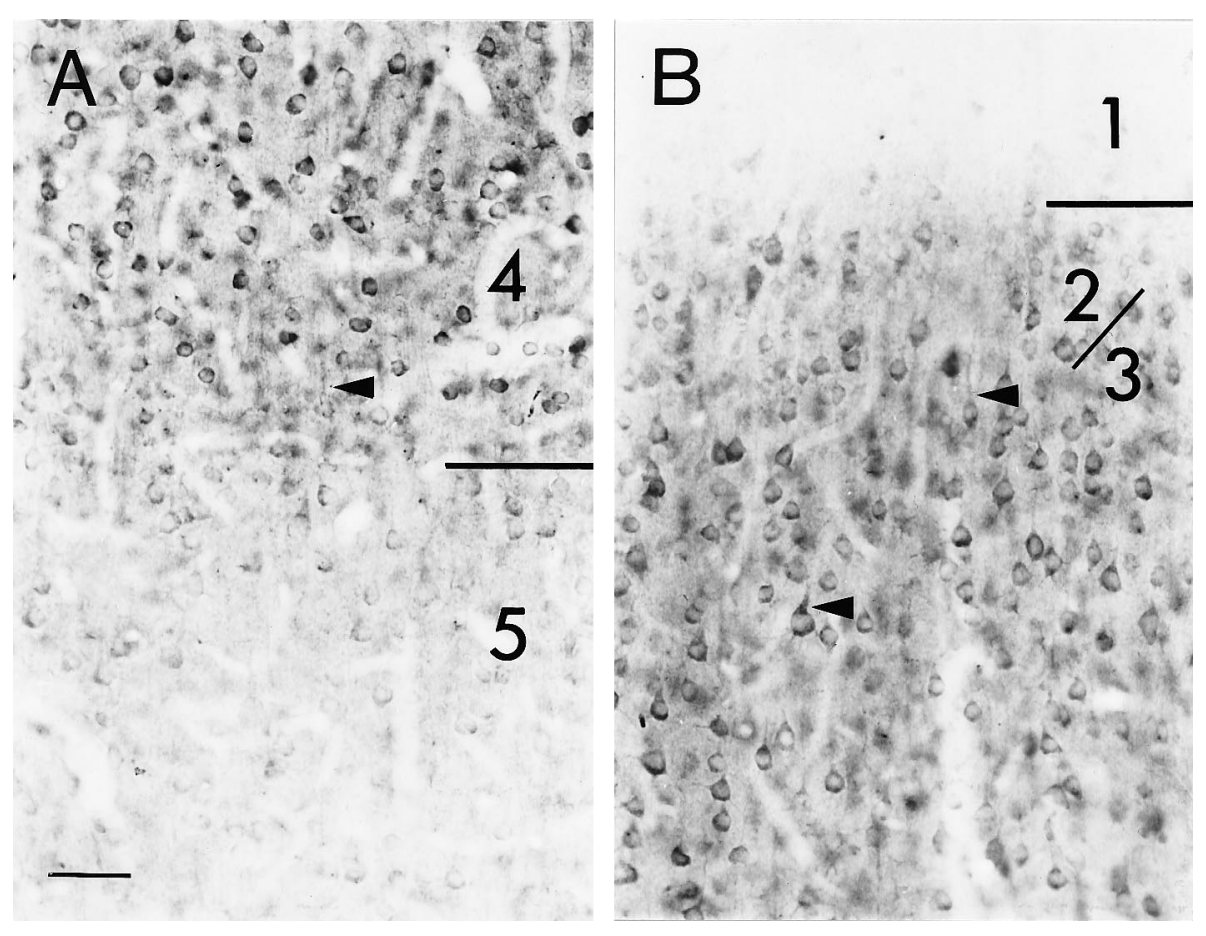

Figure 4. Photomicrograph at higher magnification showing NMDAR1 immunostained cells at the border between layers 4 and $5(A)$ and layers $2 / 3$ and $1(B)$ in a P40 cat. $A$, Many cells in layers 4 and 5 are immunoreactive, but the cells in layer 5 are far less intensely stained than those in layer 4. Both pyramidal and stellate cells are immunoreactive. $B$, The neuropil within layers $2 / 3$ is more intensely stained than that of layer 1 . Apical dendrites (arrow) appear to be as intensely immunoreactive as their parent cell soma. Scale bar (bottom left in $A$ ): $50 \mu \mathrm{m}$. to activity-dependent manipulations (Darian-Smith and Gilbert, 1994). The dramatic decline in immunostaining in layer 4 that occurs with increasing age is illustrated in Figure 5. At younger ages (P53), layers $2 / 3$ and 4 are stained with equal intensity. At older ages (P76), layer 4 is less intensely stained than layers $2 / 3$.

\section{Activity-dependent regulation of NMDAR1}

Raising animals in the dark leads to a diminution, but not complete absence, of optic nerve activity and causes changes in both NMDA receptor-mediated responses and channel activation kinetics within the cortex (Carmignoto and Vicini, 1992; Fox et al., 1992). Raising animals in the dark also extends the period during which abnormal visual experience can cause anatomical and physiological changes in cortical connectivity (Cynader and Mitchell, 1980; Mower et al., 1985; Stryker and Harris, 1986; Swindale, 1988). This period, known as the critical period, differs somewhat for different layers and for developmental changes occurring at the anatomical level (e.g., the development of ocular dominance columns) versus physiologically assessed changes in synaptic connectivity (e.g., shifts in ocular dominance caused by monocular deprivation). To examine whether levels of NMDAR1 immunoreactivity are also regulated by dark-rearing, we raised cats in the dark from shortly after birth to various ages (see Materials and Methods). We were surprised to find that dark-rearing had no effect whatsoever on either the adult pattern or the time course of laminar changes in NMDAR1 immunostaining. For example, as shown in Figure 6, the loss of NMDAR1 immunostaining in layers 4-6 still occurred in dark-reared animals by P103 (Fig. $6 E, F)$. We also examined dark-reared animals at $\mathrm{P} 15$ (Fig. $6 A, B), \mathrm{P} 28, \mathrm{P} 34$, and $\mathrm{P} 52$, and in no case was the pattern of immunostaining different from that of normal animals at the same age. Even the transient increase in layer 4 immunostaining appeared to occur at the appropriate time (Fig. 6C,D).

To obtain a direct, quantitative comparison of patterns of immunostaining between the dark-reared and normally reared animals, we computed the ratio of the average intensity of immunostaining within layers $2 / 3$ to layer 4 at each age (see Fig. 10A).
During normal development at young ages, layers $2 / 3$ are $\sim 20 \%$ darker than layer 4; by P34, staining in both layers is equivalent in intensity. At older ages, layers $2 / 3$ is almost $50 \%$ more intensely stained than layer 4 . The maximal laminar difference occurs at P76, when staining in layers $2 / 3$ is still relatively intense but staining in layer 4 has declined. Thereafter, the difference in staining between layers $2 / 3$ and 4 is less dramatic. The developmental curve of dark-reared animals is almost identical. Finally, dark-rearing followed by brief periods of exposure to the light (4 or $10 \mathrm{~d}$ ) also had no effect on immunostaining (Fig. 10 A). Thus visual experience apparently is not essential for the progressive laminar changes in levels of NMDAR1 immunoreactivity.

For comparison, developmental changes in the laminar-specific pattern of immunostaining were also examined in other areas of the neocortex in the normally reared and dark-reared cats in which primary visual cortex had been studied. There were no discernible differences in the laminar patterns of immunostaining between visual cortex and other cortical areas in either normal or dark-reared animals. In normal animals the time course of the laminar-specific changes in levels of NMDAR1 was the same over the entire neocortical mantle. For example, in primary auditory cortex of a normal P53 cat (Fig. 7A), layers 4 and 2/3 are more intensely immunoreactive than the lower layers, and this pattern of immunostaining is identical to that seen at this age in visual cortex (compare with Fig. 5A). Similarly, staining patterns in primary somatosensory cortex of a $\mathrm{P} 104$ animal (Fig. $7 C$ ) are virtually indistinguishable from those in visual cortex at the same age (compare with Fig. 6E). Primary auditory and somatosensory cortices of dark-reared animals (Fig. $7 B, D$ ) are also indistinguishable from these same areas in normal animals (compare with Fig. $7 A, C$ ). Thus, the developmental changes in the laminarspecific pattern of NMDAR1 immunostaining appear to be synchronized throughout neocortex.

The fact that dark-rearing had no obvious effect on the developmental changes in laminar-specific levels of NMDAR1 immunostaining raised the question of whether neural activity per se 


\section{CAT VISUAL CORTEX}

\section{P 53 \\ $P 76$}
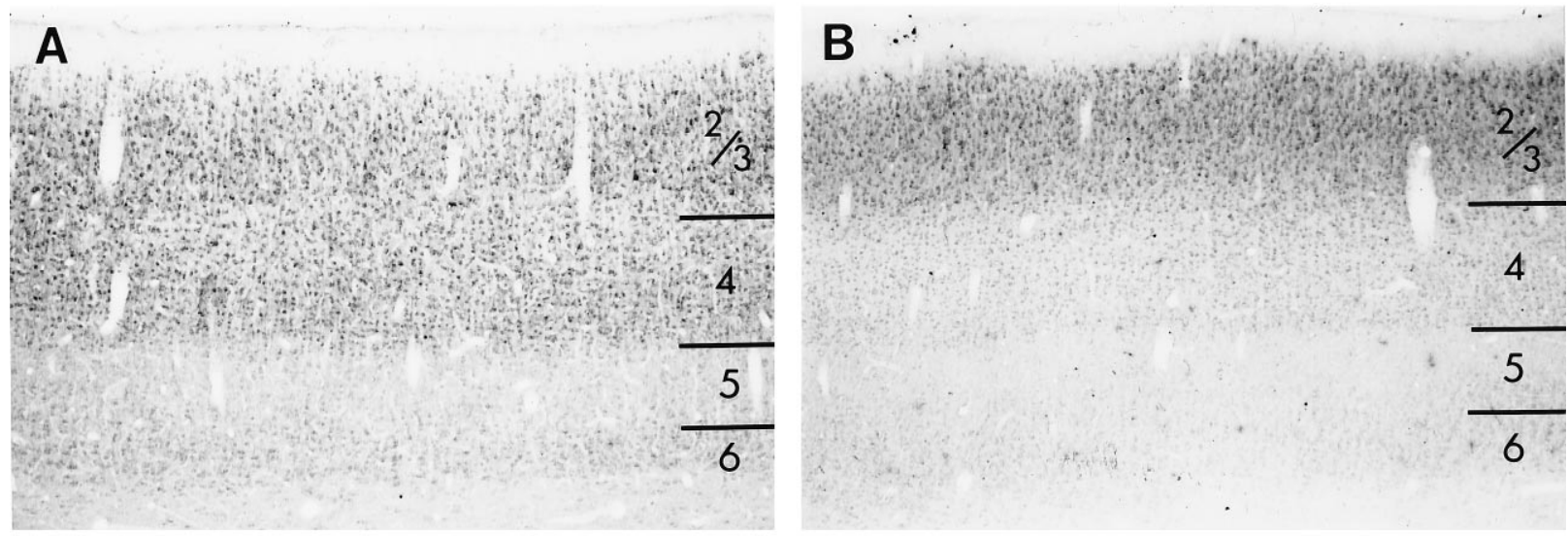

FERRET VISUAL CORTEX

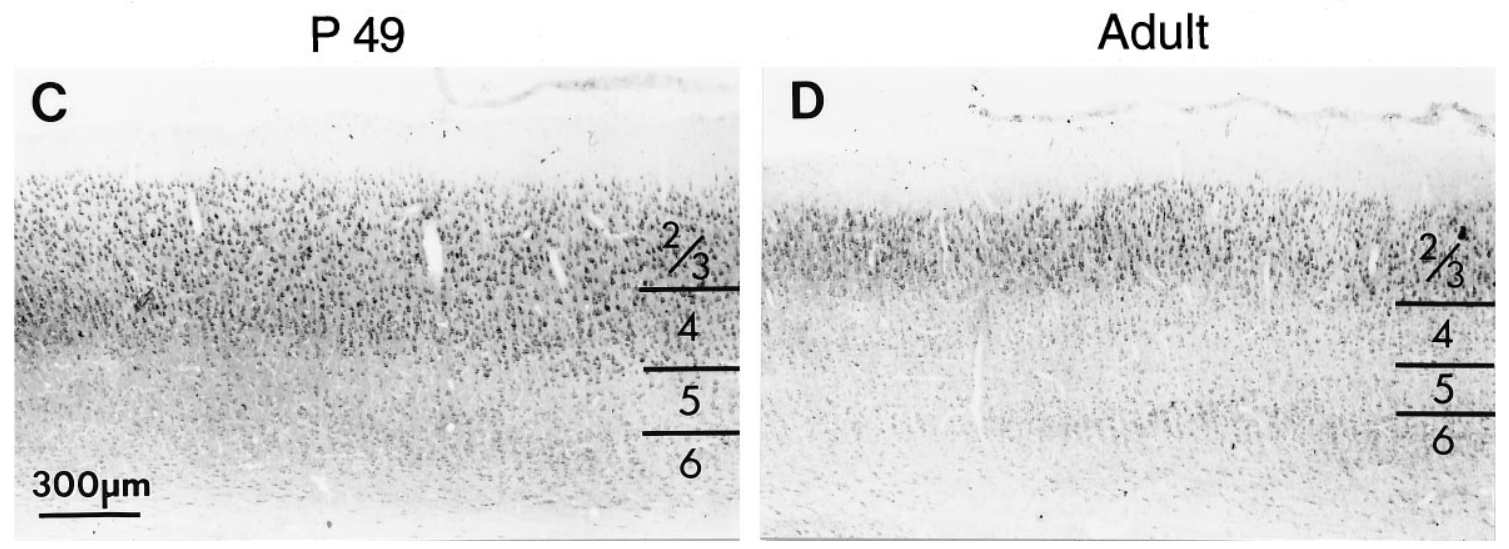

Figure 5. Decline in immunostaining for NMDAR1 in layer 4 with progressive development compared in cat (top) and ferret (bottom) visual cortex. Intensely immunoreactive cells are visible both in layers 4 and 2/3 in P52 cat $(A)$ and in P49 ferret $(C)$. At these ages, cells in layers 5 and 6 are much less intensely immunoreactive than cells in layers $2 / 3$. By the end of the cat critical period $(B)(\mathrm{P} 76)$ and in adult ferrets $(D)$, this intense immunoreactivity persists in layers $2 / 3$ but is gone from layer 4 ; cells in layer 4 exhibit staining similar to that found in the lower layers. Scale bar, $300 \mu \mathrm{m}$.

can regulate NMDAR1 protein levels. Dark-rearing does not block the spontaneous discharges of retinal ganglion cells (Mastronarde, 1989), so it is quite likely that spontaneous, retinally driven activity is still present in dark-reared animals. To block retinal activity entirely, and to have a means of comparing the effects of such a blockade directly within the same animal, we performed an experiment in which TTX, a blocker of voltagesensitive $\mathrm{Na}^{+}$channels, was injected intraocularly into one eye for 2 weeks from P40-53. At P40, the ocular dominance columns have just formed within layer 4 (LeVay et al., 1978), making it possible to examine whether activity blockade in one eye can alter the levels of immunostaining for NMDAR1 in cortical columns associated with that eye.

The pattern of NMDAR1 immunostaining after monocular TTX injections was dramatically different from that seen in untreated animals of the same age (compare Fig. $8 A$ with Fig. $5 A$ ). In the TTX-treated animals, there was a distinct waxing and waning of immunostaining in cortical layer 4. To determine whether the zone of relatively high-intensity NMDAR1 immunostaining corresponded to the untreated versus the treated eye, adjacent sections were reacted for cytochrome oxidase $(\mathrm{CO})$ histochemistry. A decline in CO staining within layer 4 is known to be associated with the columns of the blocked eye (WongRiley, 1979; Murphy et al., 1995). As shown in Figure $8 A, B$, there is a clear association between zones of diminished $\mathrm{CO}$ staining and regions of lighter NMDAR1 immunostaining. This indicates that TTX treatment resulted in a decrease in levels of NMDAR1 within layer 4 relative to NMDAR1 levels in layer 4 patches associated with the uninjected eye. In contrast, there was no effect of TTX injections on immunostaining within layers $2 / 3$, which remained uniform (but see Murphy et al., 1996). Similarly, immunostaining of other cortical areas in these same animals was uniform, as was immunostaining of layer 4 in an animal that received an intraocular injection of citrate vehicle alone (Fig. 9). This result suggests that retinal activity can indeed regulate levels of NMDAR1 immunoreactivity, chiefly within cortical layer 4.

To characterize these changes further, digital images of tissue sections were obtained using a video camera, and immunostaining intensity was expressed as units of pixel gray values. The average immunostaining intensity within layer 4 over a span of 2.5 mm was then plotted (Fig. 9). In sections from animals that had received monocular TTX injections between P40 and P52, fluc- 


\section{NORMAL}
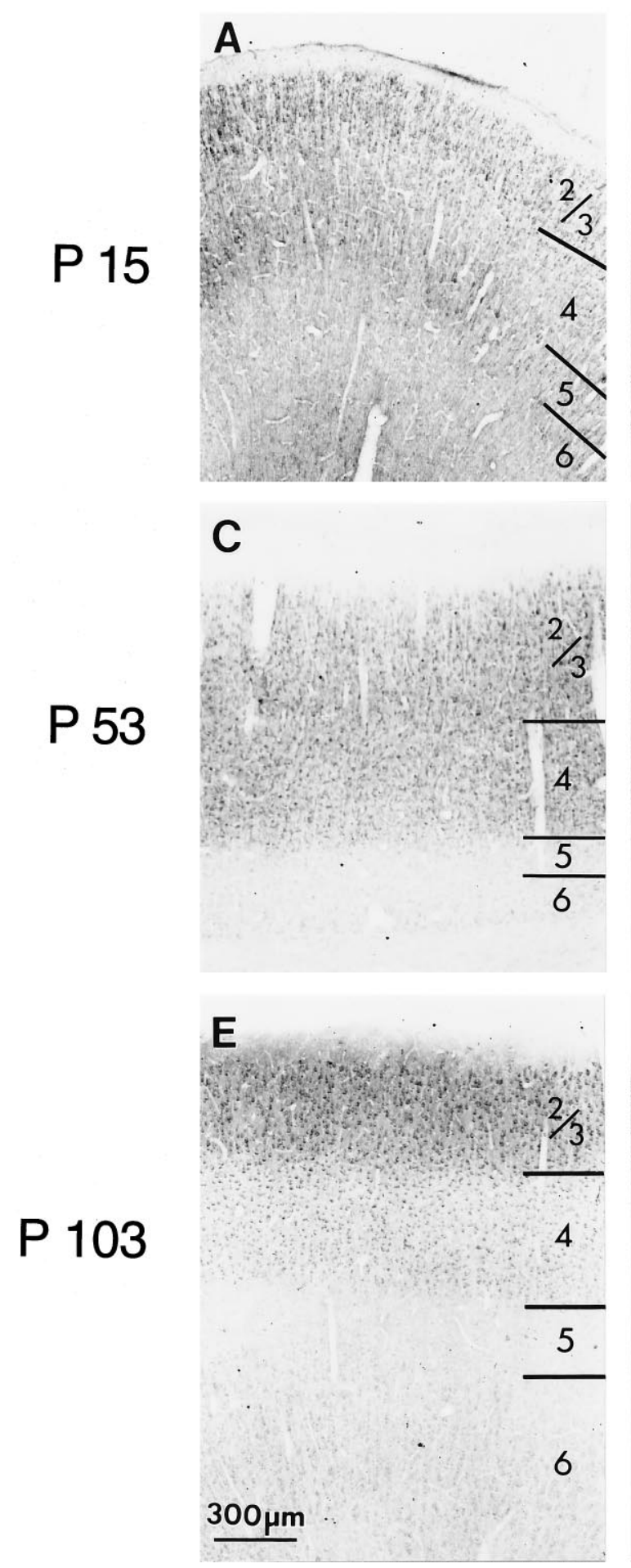

\section{DARK-REARED}
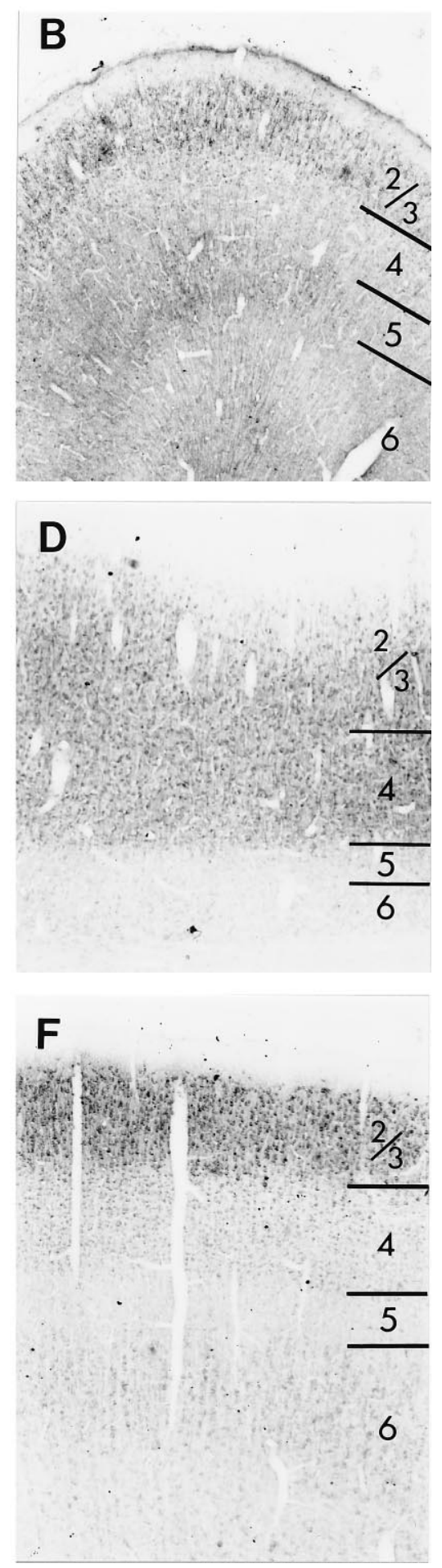

Figure 6. Dark-rearing does not alter the laminar pattern of immunostaining in primary visual cortex. At $\mathrm{P} 15$ in both normal cats $(A)$ and after 2 weeks of dark-rearing beginning at $\mathrm{P} 1(B)$, layers $2 / 3$ and 5 are stained most intensely. At P53, layer 4 is equally as intensely stained as layers $2 / 3$ in both normal $(C)$ and dark-reared $(D)$ animals. At P104, the visual cortex of normal animals $(E)$ and animals dark-reared from shortly after birth $(F)$ exhibit high levels of immunostaining in layers $2 / 3$, whereas layers $4-6$ are stained less intensely. Scale bar, $300 \mu \mathrm{m}$. tuations in the intensity of NMDAR1 immunostaining within layer 4 are clearly visible (Fig. $9 A, B$ ). The peak-to-trough periodicity of these fluctuations is $\sim 0.5 \mathrm{~mm}$, which roughly corresponds in the cat to the dimensions of ocular dominance columns (Shatz et al., 1977; LeVay et al., 1978). No such periodicity in NMDAR1 immunoreactivity is present within layer 4 of either a control animal monocularly injected with citrate buffer vehicle (Fig. 9C) or a normal untreated animal of the same age (Fig. 9D).
Similarly, no such fluctuations in immunostaining intensity are present in superficial layers $2 / 3$ or layer 6 of TTX-treated animals (Fig. 9E). Finally, as shown in the histograms of Figure $10 B$, there is no significant difference in the ratio of layers $2 / 3$ /layer 4 staining between normal animals and animals in which citrate vehicle was injected into one eye ( $p<0.15$; two-tailed $t$ test) (Fig. $10 B)$. There is also no significant difference in the ratio of layers 2/3/layer 4 staining between normal animals and columns in the 


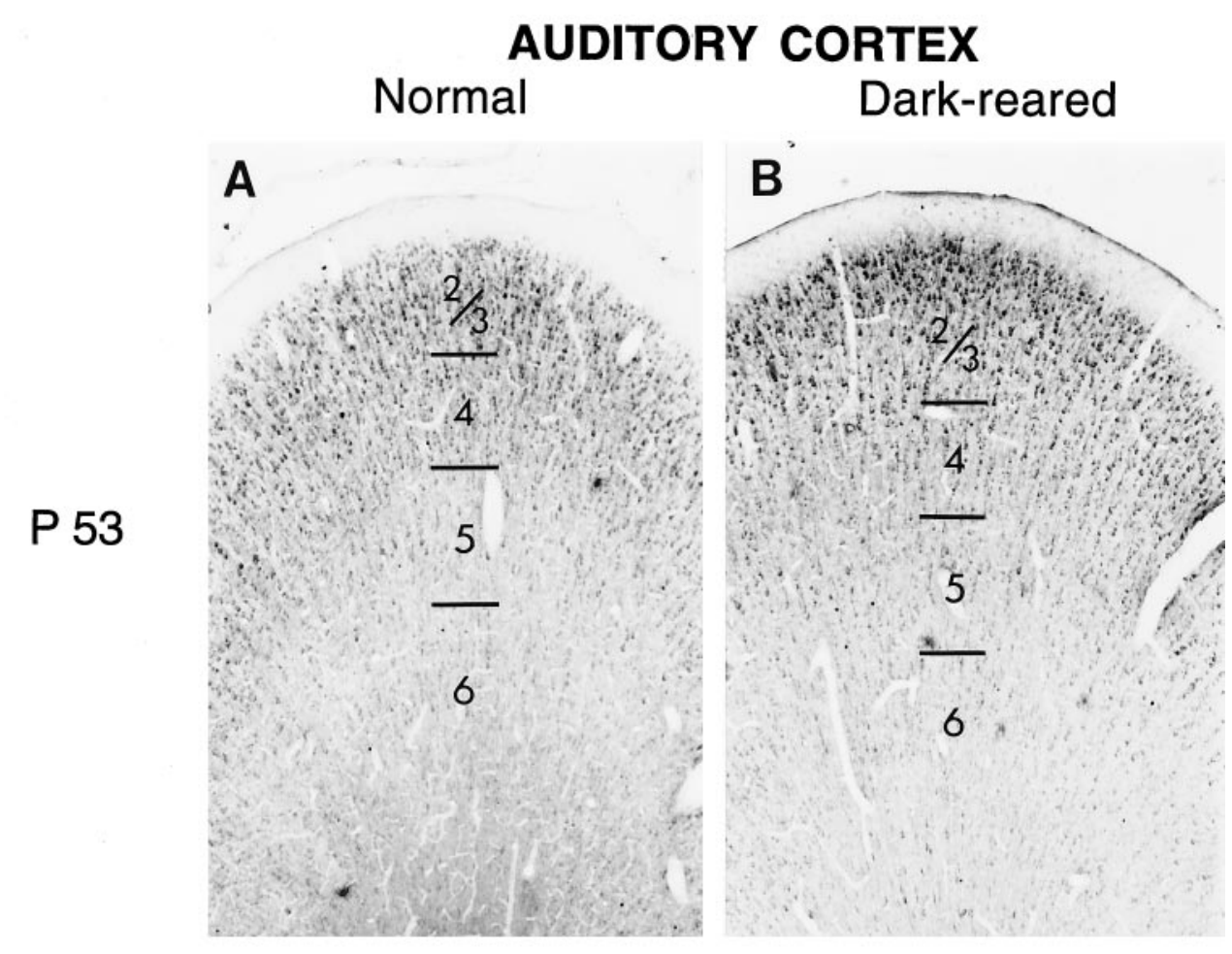

Figure 7. Developmental changes in laminar patterns of NMDAR1 immunostaining occur over the same time period throughout cat neocortex. $A$, Primary auditory cortex at P53. $B$, Primary auditory cortex at P53 in an animal dark-reared from shortly after birth to P53. Layers 4 and $2 / 3$ are more intensely immunoreactive than the lower layers, and darkrearing does not affect this pattern of staining. $C$, Primary somatosensory cortex of normal animal aged P104. D, Primary somatosensory cortex in an animal darkreared to P104. At this age, somatosensory cortex exhibits relatively intense staining for NMDAR1 in layers $2 / 3$ but not in the other layers. These same laminar-specific patterns of immunostaining are seen in visual cortex at the same ages (compare with Figs. $5 A, 6 E$ ). Scale bar, $300 \mu \mathrm{m}$.

\section{P 103}

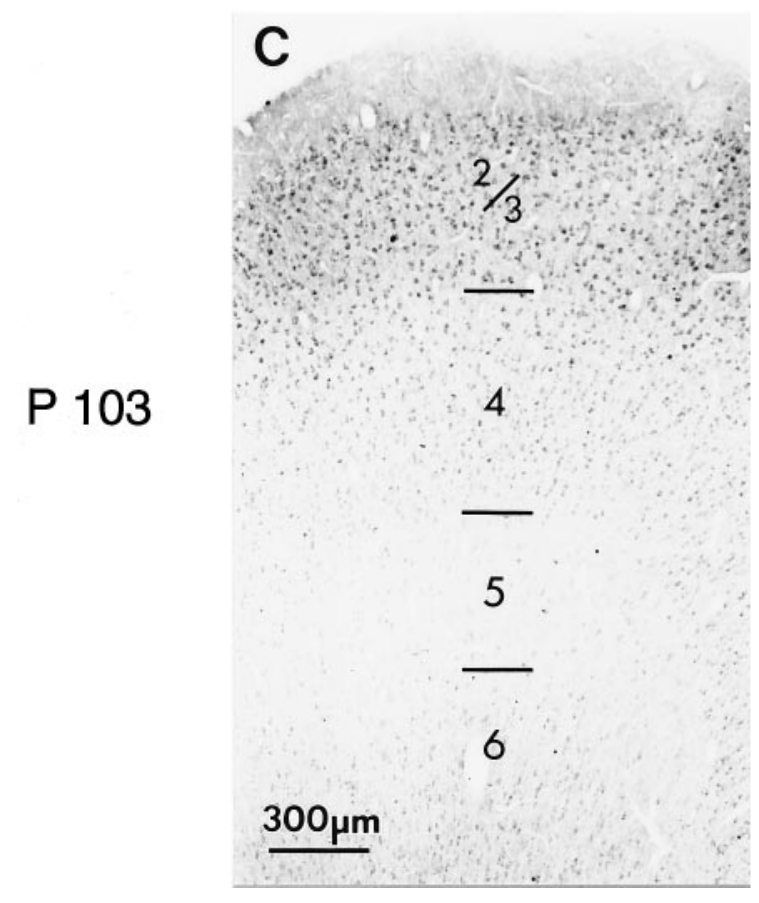

\section{SOMATOSENSORY CORTEX} Normal

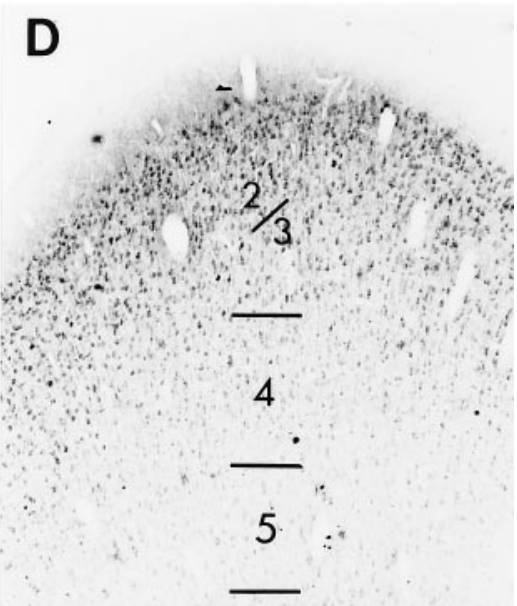

6 noninjected eye in animals that received monocular injections of TTX $(p<0.005)$. In contrast, the ratios between layers $2 / 3$ and layer 4 in the columns of the injected eye in the TTX-treated animals is significantly different from normal $(p<0.00005)$, reflecting the large decrease in immunostaining intensity within layer 4 pertaining to the TTX-treated eye. These observations lend quantitative support to the conclusion that retinal activity blockade can indeed dramatically modulate levels of NMDAR1 within developing visual cortex.

\section{DISCUSSION}

Here we have used an antibody to the R1 subunit of the NMDA receptor to monitor immunohistochemical changes in the distri- 


\section{Monocular TTX injections P 40-53}

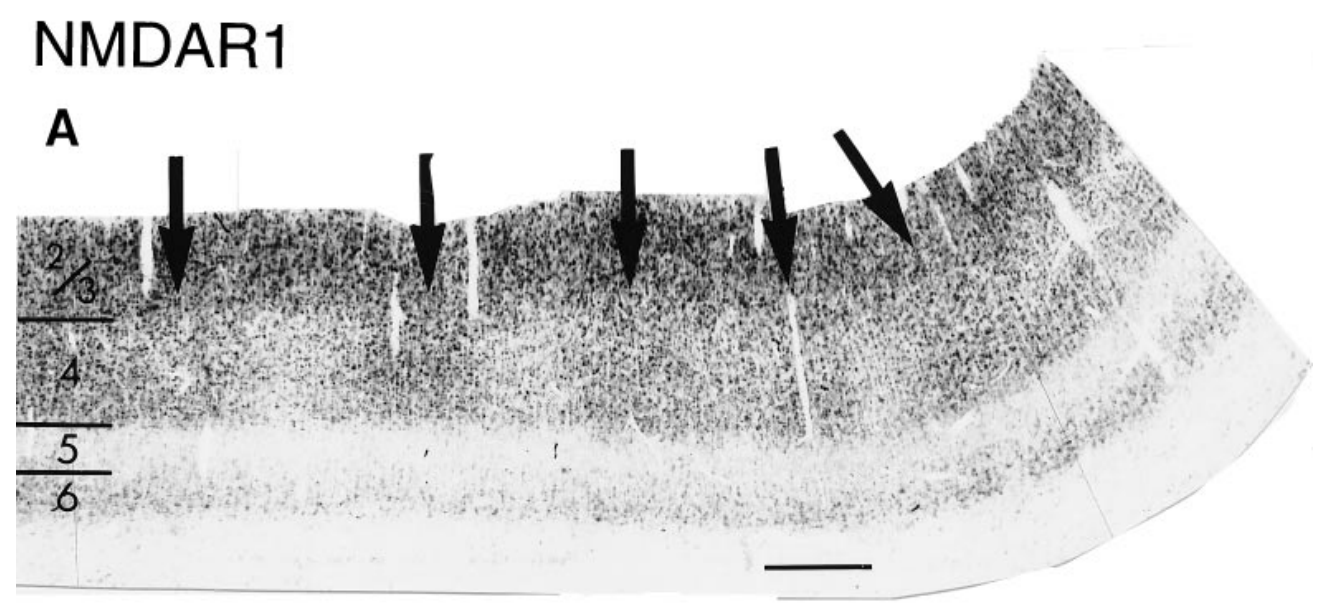

\section{Cytochrome Oxidase}

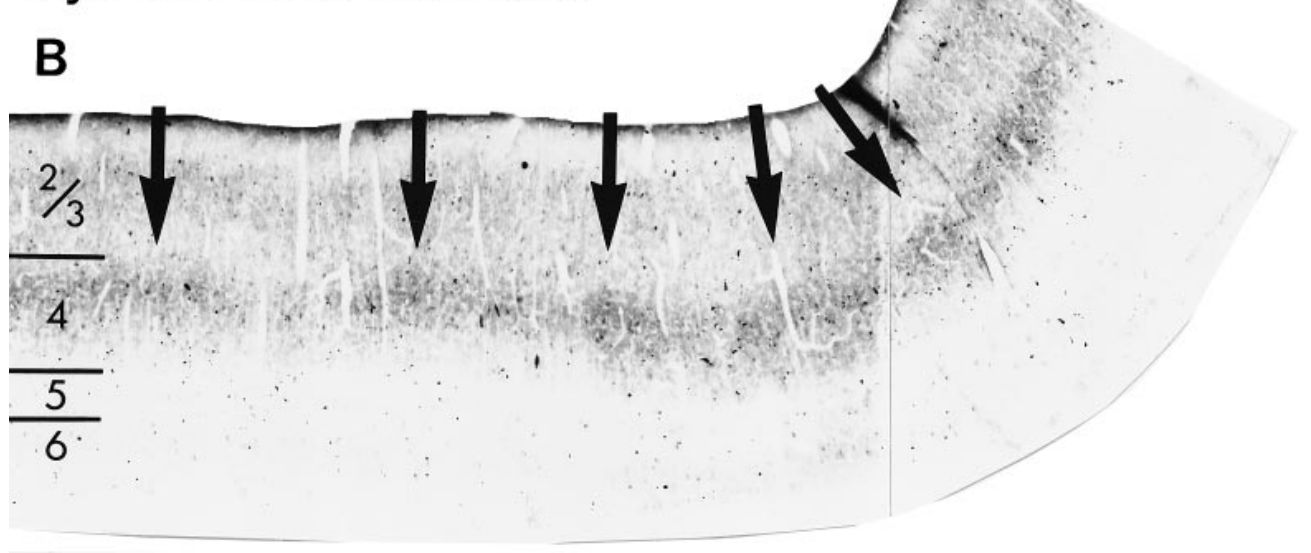

Figure 8. Monocular TTX injection from P40 to P53 decreases NMDAR1 immunostaining in injected eye columns of layer 4 in cat visual cortex. Adjacent sections stained for NMDAR1 immunocytochemistry $(A)$ or for $\mathrm{CO}$ histochemistry $(B)$. Note higher levels of NMDAR1 immunostaining $(A)$ and $\mathrm{CO}$ activity $(B)$ in patches (arrows) in layer 4 corresponding to the uninjected eye. Scale bar (shown in $A$ ): $500 \mu \mathrm{m}$. bution of NMDA receptors in the development of the cat and ferret visual cortex. Results indicate that there are sequential changes in the laminar pattern of immunostaining; these are summarized schematically in Figure 11. The most striking of these changes includes a permanent decrease in immunoreactivity within cortical layers 5 and 6 , a transient developmental increase in layer 4 immunostaining, and a persistence of immunostaining in layers $2 / 3$ into adulthood.

\section{Developmental changes in NMDAR1 immunoreactivity correlate with periods of synaptic remodeling}

Levels of NMDAR1 immunoreactivity are high in layer 4 during the period of development when geniculocortical axons are remodeling their terminal arbors to form columnar patterns of connections. In the cat visual cortex, segregation of initially overlapping geniculocortical axon terminals representing each eye within layer 4 into ocular dominance columns begins at approximately 3 weeks of age and is nearly adult-like by 6 weeks (LeVay et al., 1978; Antonini and Stryker, 1993b). R1 levels peak in layer 4 by approximately 4 weeks (P35) and fall to adult levels by 11 weeks (P76), when anatomical rearrangements of geniculocortical axons can no longer be induced (Mower et al., 1985). Physiologically, NMDA receptors make a similar contribution to the visu- ally driven activity of neurons in all cortical layers initially; however, between 3 and 6 weeks, this contribution declines in layers 4-6 and remains high in layers 2/3 (Tsumoto et al., 1987; Fox et al., 1989). Thus, our immunocytochemistry observations of laminar patterns of R1 levels correlate with the physiological changes, albeit at a slight temporal lag.

There is also a clear correlation in layers $2 / 3$ between high levels of NMDAR1 immunoreactivity and known periods of axonal growth and synaptic plasticity. In these superficial layers, the pattern of lateral axonal connections develops over the same time course as that for the geniculocortical axons (Callaway and Katz, 1990; Ruthazer and Stryker, 1996). However, unlike layer 4, in which major axonal remodeling appears to end with the close of the critical period, evidence suggests that the capacity for axonal remodeling of horizontal connections persists in layers $2 / 3$ into adulthood (Darian-Smith and Gilbert, 1994). Physiologically, the effects of monocular deprivation on the ocular dominance preference of neurons in the superficial layers can be demonstrated in animals as old as 1 year, long after eye dominance in layer 4 can no longer be altered (Daw et al., 1992), and there is accumulating evidence that the receptive fields of neurons in layers $2 / 3$, but not layers $4-6$, can be altered dynamically in adults 


\section{NMDAR1 Immunostaining in Layer 4}
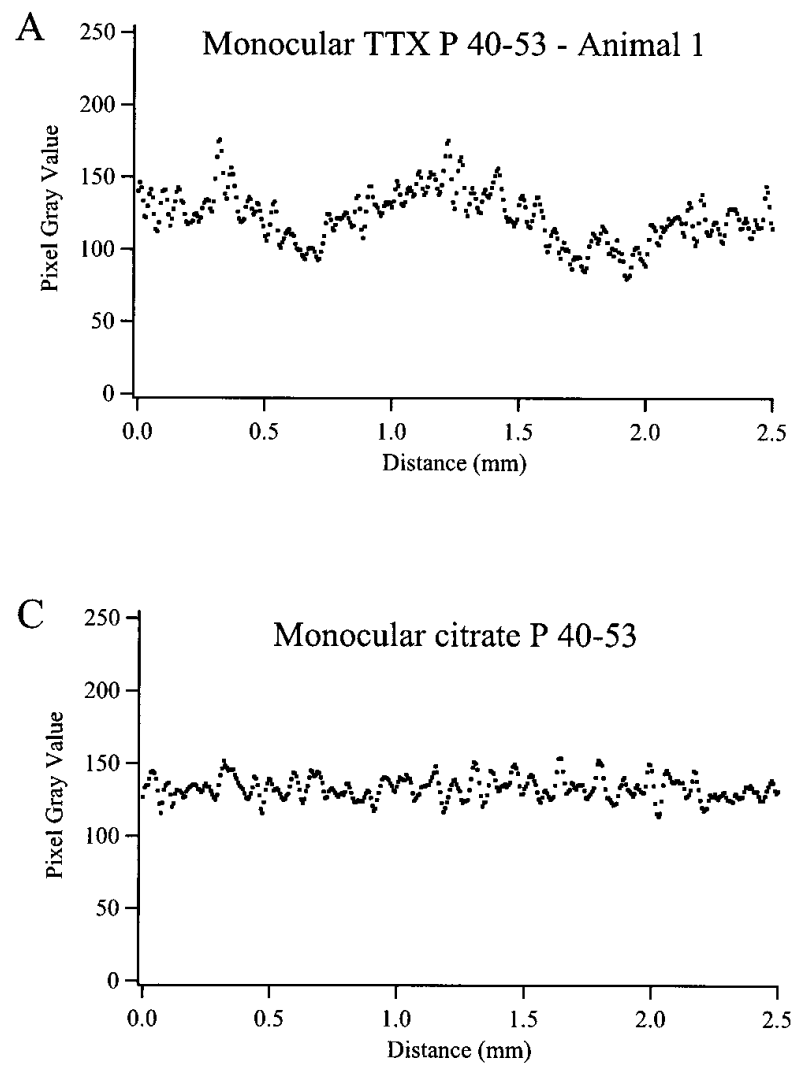

NMDAR1 Immunostaining in Layers $2 / 3$ and 6 of

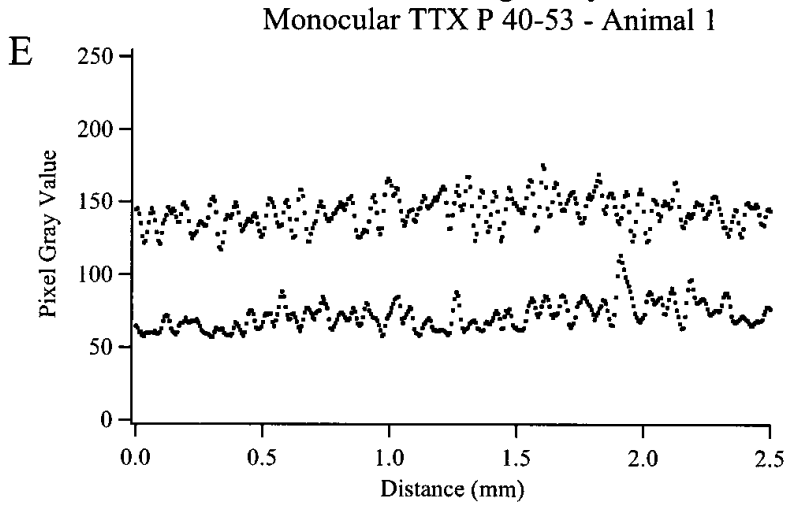

by certain patterns of visual stimulation (Das and Gilbert, 1995). The finding here that the levels of NMDAR1 immunostaining remain high within layers $2 / 3$ into adulthood is entirely consistent with an ongoing role for NMDA receptors in modulating plasticity within these specific superficial layers.

Taken together, our data suggest that high levels of NMDAR1 immunoreactivity within the visual cortex are correlated with periods in development (or in the adult) when the capacity for anatomical and physiological synaptic plasticity is possible, depending on cortical layer. In addition, we observed that developmental changes in the laminar pattern of NMDAR1 immunore-
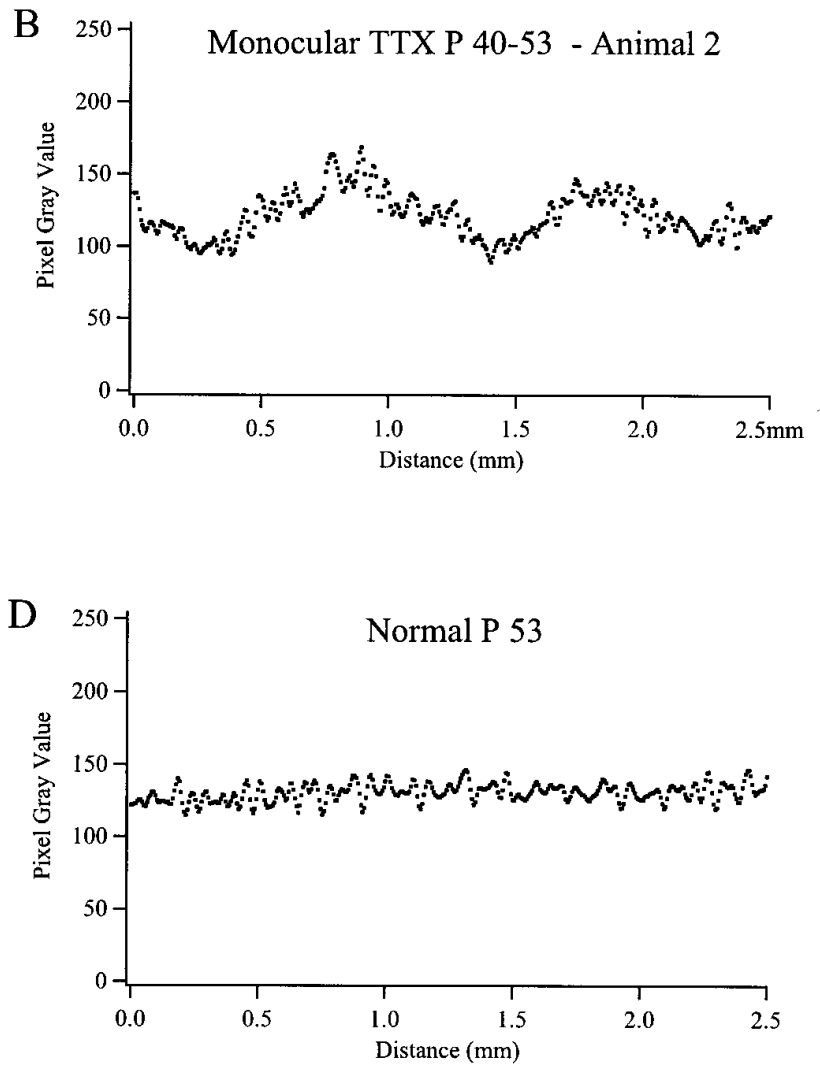

Layer $2 / 3$
Figure 9. Periodic fluctuations in NMDAR1 immunostaining intensity occur within layer 4 of two animals monocularly injected with TTX from P40-53 $(A, B)$. No such fluctuations are present within layer 4 of control citrate buffer-injected $(C)$ or normal $(D)$ age-matched animals, or within layers $2 / 3$ and 6 of the TTXinjected animal shown in $A(E)$ (see Materials and Methods for details). activity occur with the same time course in all cortical areas examined. Several other aspects of cortical development appear to be synchronized across all areas of cortex. For example, the time course of both synaptogenesis and the development of relative proportions of different types of synapses are the same in visual, motor, somatosensory, and prefrontal cortical areas of monkeys (Bourgeois et al., 1994). As these authors suggest, synchronous maturation of certain aspects of cortical development may be required to coordinate the development of particular cortical features such as the network of intracortical connections. If NMDA receptors play a crucial role in synaptic remodeling in 

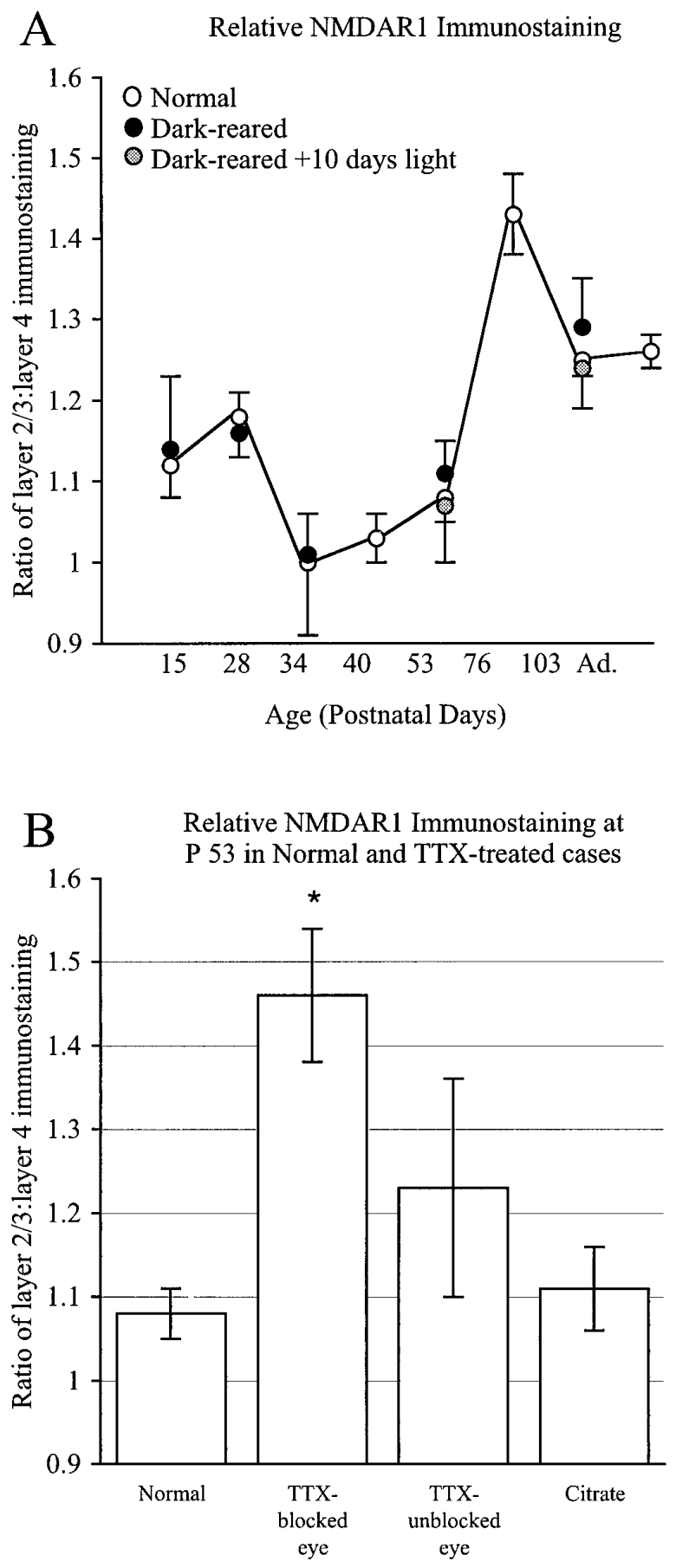

Figure 10. Ratio of layers 2/3/layer 4 NMDAR1 immunostaining intensity compared across ages and experimental conditions in cats $( \pm \mathrm{SD})$. Average immunostaining levels were calculated for each layer from digitized images, and ratios were determined. $A$, Comparison of developmental changes in the ratios for normally reared or dark-reared animals. Layers $2 / 3$ are consistently darker than layer 4 at most ages except between P34 and 53, when the two layers are equivalent in intensity $(A)$. There is no significant difference in immunostaining ratios between normal animals and agematched dark-reared animals or dark-reared animals exposed to light. $B$, Ratios for normally reared and monocularly TTX-treated cases shown in histogram form. Immunostaining intensity ratios do not vary significantly between normal P53 animals and control animals receiving monocular injections of citrate between P40 and P53 $(p<0.15)(B)$ or from the columns pertaining to the unblocked eye $(p<0.005)$. However, note that immunostaining ratios obtained from the columns of the TTX-injected eye are significantly greater than those from normal animals $(p<0.00005$; two-tailed $t$ test). cortex, it may be important to synchronize their expression throughout cortex, and if so, then the changes seen here in NMDAR1 immunostaining could reflect this synchrony.

The distribution of NMDA receptors has been studied previously using autoradiographic ligand binding on tissue sections of both developing cat (Bode-Greuel and Singer, 1989) and adult ferret visual cortex (Smith and Thompson, 1994). Contrary to the present results, the cat study concluded that layers 4 and $5 / 6$ exhibited similar levels of binding sites throughout development, and that binding sites in all layers increased gradually to a peak at 12 weeks and then declined into adulthood. The ligand binding study in adult ferrets suggests that NMDA receptors are expressed equally in all layers of cortex, with binding in layers 4 and 1 slightly higher than in other layers. Methodological differences such as the increased spatial resolution provided here by immunocytochemistry and the dependence of ligand binding on the physiological state of the receptor may account for the differences seen between these studies and the present results.

A temporal correlation exists between the period of high levels of NMDAR1 immunostaining in the visual cortex and the presence of neocortical long-term potentiation (LTP) and long-term depression (LTD). NMDA receptor-dependent LTP and LTD can be evoked in slices of cat and rat visual cortex and rat somatosensory cortex from young animals. At older ages and in adulthood, LTP and LTD can no longer be induced in layer 4 but can still be induced in layers 2/3 (Komatsu et al., 1988; Perkins and Teyler, 1988; Kirkwood and Bear, 1994; Castro-Alamancos et al., 1995; Crair and Malenka, 1995; Dudek and Friedlander, 1996; Isaac et al., 1997; for review, see Bear and Malenka, 1994). Changing levels of NMDAR1 seen here may partially account for the changing capacity for LTP and LTD during development.

\section{Regulation of NMDAR1 immunoreactivity by vision and activity}

Dark-rearing did not alter either the time course or the laminar pattern of immunostaining for NMDAR1 in visual cortex, and this observation was surprising in view of the results of several previous physiological studies. Normally, the duration of the NMDA receptor-mediated EPSC shortens over development, but dark-rearing or TTX administration can prevent this shortening (Carmingnoto and Vicini, 1992). Similarly, the normal developmental decrease in the percentage of the visually driven response mediated by NMDA receptors is prevented when cats are raised in the dark and resumes when dark-reared animals are subsequently exposed to light (Fox et al., 1989, 1991, 1992). Our results suggest that the physiological alterations that occur during darkrearing do not result from major changes in the amount of NMDAR1 protein. However, NMDA receptor subunit composition (Sheng et al., 1994; Flint et al., 1997) and/or phosphorylation state (Roche et al., 1994; Tingley et al., 1997) may change with dark-rearing, because both have also been shown to affect channel function.

Because the normal developmental loss of NMDAR1 immunostaining from layer 4 is not prevented by dark-rearing, vision evidently is not required for this sequential maturational change. Vision is also not required for the progressive segregation of LGN axons to form the system of ocular dominance columns in layer 4 (Mower et al., 1985; Stryker and Harris, 1986). Darkrearing, however, does not abolish all retinal activity. What remains is spontaneous activity generated among retinal ganglion cells (Meister et al., 1991; Wong et al., 1993, 1995; Feller et al., 


\section{NMDAR1 IMMUNOREACTIVITY IN CAT NEOCORTEX}

E 42

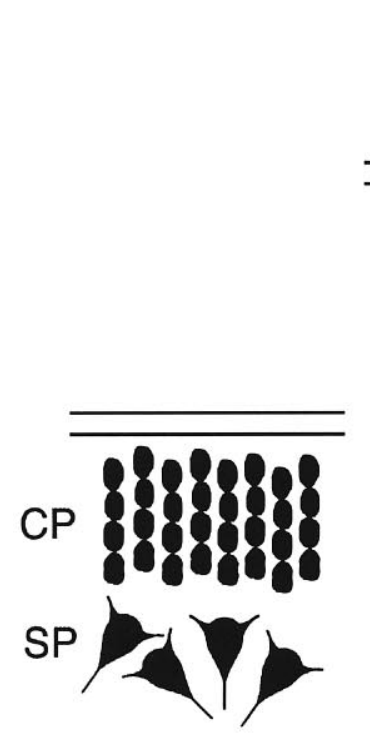

P 0
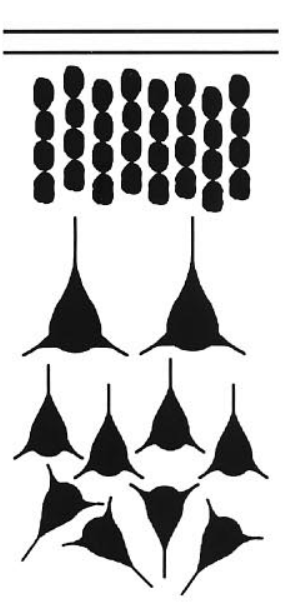

P $15 \quad P 28$
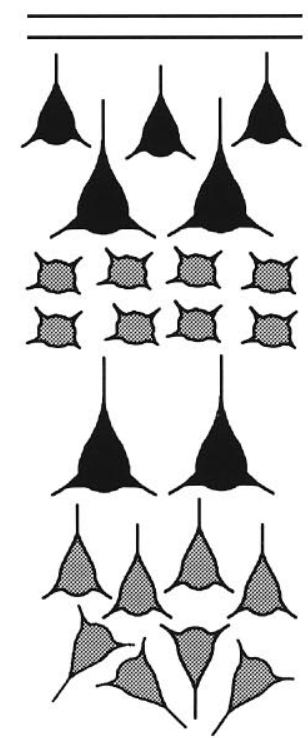

P 34 P 40 P 53
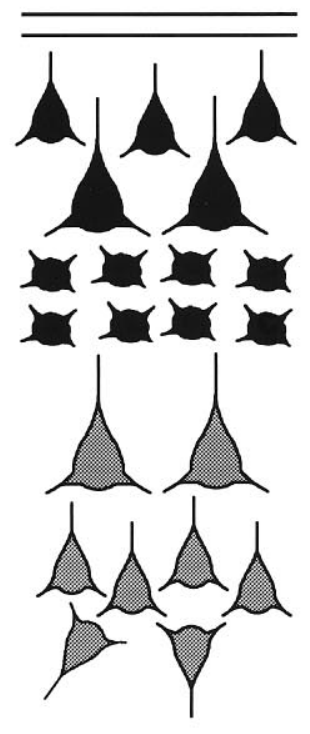

P 76 P 103 Adult

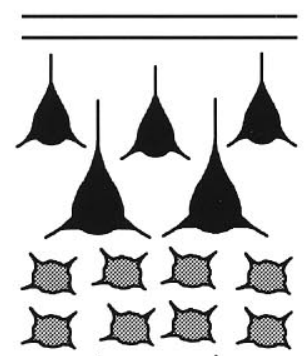

1

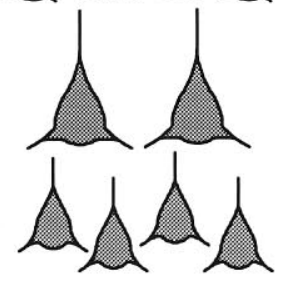

$$
\begin{array}{cccc}
\text { P 5 } & \text { P 22 } & \text { P } 40 & \text { P 71-112 } \\
\text { Eye opening } & \begin{array}{c}
\text { Ocular dominance } \\
\text { column formation } \\
\text { in layer 4 begins }
\end{array} & \begin{array}{c}
\text { Columns are } \\
\text { clearly present } \\
\text { in layer } 4
\end{array} & \begin{array}{c}
\text { End of the critical } \\
\text { period in layer } 4
\end{array} \\
\hline
\end{array}
$$

Figure 11. Summary of developmental changes in the laminar pattern of NMDAR1 immunoreactivity in cat neocortex. Ages at the top correspond to those examined in this study. Each cortical layer is represented by its most prominent cell type (large or small pyramidal or stellate cells). Black cells indicate high levels of NMDAR1 immunostaining; gray cells are stained less intensely. The bar at the bottom of figure is a timeline of the major anatomical events in cat visual cortex development. Note gradual decline in immunostaining of deep cortical layers (5 and 6) with age, transient elevation of staining in layer 4 between P34 and P53, and maintenance of high levels of immunostaining in layers 2/3 into adulthood.

1996). These considerations suggest that spontaneous retinal activity may be sufficient to drive the laminar changes in distribution of NMDAR1. On the other hand, the synchronous changes observed here in laminar patterns of NMDAR1 immunoreactivity across many neocortical areas imply that changes in neural activity would have to be coordinated across many different functional modalities. Thus, an alternative possibility is that intrinsic activity-independent mechanisms, or neural activity not necessarily related to sensory stimulation, is responsible for the sequential changes in the laminar distribution of NMDAR1 within neocortex.

Although dark-rearing does not alter developmental changes in the pattern of NMDAR1 immunostaining, monocular TTX injections between $\mathrm{P} 40$ and P53 result in a profound alteration in levels of NMDAR1 in layer 4 of the visual cortex. Normally at P40 and P53, the levels of NMDAR1 immunostaining in layer 4 are relatively high and fall thereafter to adult levels. Monocular blockade of activity caused a dramatic decrease in immunostaining in layer 4 ocular dominance columns receiving input from the blocked eye. Thus it would seem that NMDAR1 levels can indeed be regulated by alterations in neural activity under some circumstances: when retinal activity is eliminated entirely.

It should be noted that monocular blockade has very different consequences from dark-rearing or even binocular TTX blockade for spatial patterns of neural activity within cortex. At P40, at the onset of the monocular TTX blockade, segregation of LGN axons into ocular dominance columns is well on the way to completion, and most layer 4 neurons are already monocularly driven (LeVay et al., 1978). Consequently, layer 4 neurons receiving input from the blocked eye will not only be silenced because of lack of functional geniculocortical inputs, but they may also receive strong local inhibition from adjacent unblocked eye columns. This profound imbalance of activity may be necessary to cause a decrease in NMDAR1 levels. Such an imbalance of activity between blocked and unblocked columns in layer 4 could also explain why monocular TTX injections failed to produce alterations in NMDAR1 immunostaining in layers $2 / 3$. Neurons in these cortical layers are normally binocularly driven (Shatz and Stryker, 1978) and would be expected to continue to receive powerful synaptic drive from layer 4 neurons belonging to the unblocked eye. Future experiments in which cortical activity is manipulated directly could help unravel the extent to which activity-dependent versus activity-independent processes contribute to the regulation of NMDAR1. Suffice it to say that our experiment provides clear evidence that profound alterations in the balance of afferent activity from the two eyes can indeed alter NMDAR1 levels in layer 4 of the visual cortex. 


\section{REFERENCES}

Antonini A, Stryker MP (1993a) Rapid remodeling of axonal arbors in the visual cortex. Science 260:1819-1821.

Antonini A, Stryker MP (1993b) Development of individual geniculocortical arbors in cat striate cortex and effects of binocular impulse blockade. J Neurosci 13:3549-3573.

Bear MF (1996) NMDA-receptor-dependent synaptic plasticity in the visual cortex. Prog Brain Res 108:205-218.

Bear MF, Colman H (1990) Binocular competition in the control of geniculate size depends upon visual cortical $N$-methyl-D-aspartate receptor activation. Proc Natl Acad Sci USA 87:9246-9249.

Bear MF, Malenka RC (1994) Synaptic plasticity: LTP and LTD. Curr Opin Neurobiol 4:389-399.

Bear MF, Kleinschmidt A, Gu Q, Singer W (1990) Disruption of experience-dependent synaptic modifications in striate cortex by infusion of an NMDA receptor antagonist. J Neurosci 10:909-925.

Bode-Greuel K, Singer W (1989) The development of $N$-methyl-Daspartate receptors in cat visual cortex. Dev Brain Res 46:197-204.

Bourgeois J-P, Goldman-Rakic PS, Rakic P (1994) Synaptogenesis in the prefrontal cortex of rhesus monkeys. Cereb Cortex 4:78-96.

Brose N, Thomas A, Weber MG, Jahn R (1990) A chloride- and calcium-dependent glutamate-binding protein from rat brain. Identification as a ubiquitous constituent of the inner mitochondrial membrane. J Biol Chem 265:10604-10610.

Brose N, Huntley GW, Stern-Bach Y, Sharma G, Morrison JH, Heinemann SF (1994) Differential assembly of coexpressed glutamate receptor subunits in neurons of rat cerebral cortex. J Biol Chem 269:16780-16784.

Callaway EM, Katz LC (1990) Emergence and refinement of clustered horizontal connections in cat striate cortex. J Neurosci 10:1134-1153.

Callaway EM, Katz LC (1991) Effects of binocular deprivation on the development of clustered horizontal connections in cat striate cortex Proc Natl Acad Sci USA 88:745-749.

Carmignoto G, Vicini S (1992) Activity-dependent decrease in NMDA receptor responses during development of the visual cortex. Science 258:1007-1011.

Castro-Alamancos MA, Donoghue JP, Connors B (1995) Different forms of synaptic plasticity in somatosensory and motor areas of the neocortex. J Neurosci 15:5324-5333.

Cline H, Constantine-Paton M (1990) NMDA receptor agonist and antagonists alter RGC terminal morphology in the frog retinotectal projection. J Neurosci 10:1197-1216.

Crair MC, Malenka RC (1995) A critical period for long-term potentiation at thalamocortical synapses. Nature 375:325-328.

Cynader M, Mitchell DE (1980) Prolonged sensitivity to monocular deprivation in dark-reared cats. J Neurophysiol 43:1026-1040.

Darian-Smith C, Gilbert CD (1994) Axonal sprouting accompanies functional reorganization in adult cat striate cortex. Nature 368:737-740.

Das A, Gilbert CD (1995) Receptive field expansion in adult visual cortex is linked to dynamic changes in strength of cortical connections. J Neurophysiol 74:779-792.

Daw NW, Fox K, Sato H, Czepita D (1992) Critical period for monocular deprivation in the cat visual cortex. J Neurophysiol 67:197-202.

Dudek SM, Friedlander MJ (1996) Developmental down-regulation of LTD in cortical layer IV and its independence of modulation by inhibition. Neuron 16:1097-1106.

Feller MB, Wellis DP, Stellwagen D, Werblin FS, Shatz CJ (1996) Requirement for cholinergic synaptic transmission in the propagation of spontaneous retinal waves. Science 272:1182-1187.

Flint AC, Maisch US, Weishaupt JH, Kriegstein AR, Monyer H (1997) NR2A subunit expression shortens NMDA receptor synaptic currents in developing neocortex. J Neurosci 17:2469-2476.

Fox K, Daw NW (1993) Do NMDA receptors have a critical function in visual cortical plasticity? Trends Neurosci 16:116-122.

Fox K, Sato H, Daw N (1989) The location and function of NMDA receptors in cat and kitten visual cortex. J Neurosci 9:2443-2454.

Fox K, Daw N, Sato H, Czepita D (1991) Dark-rearing delays the loss of NMDA-receptor function in kitten visual cortex. Nature 350:342-344.

Fox K, Daw N, Sato H, Czepita D (1992) The effect of visual experience on development of NMDA receptor synaptic transmission in kitten visual cortex. J Neurosci 12:2672-2684.

Fox K, Schlaggar BL, Glazewski S, O'Leary DDM (1996) Glutamate receptor blockade at cortical synapses disrupts development of thalamocortical and columnar organization in somatosensory cortex. Proc Natl Acad Sci USA 93:5584-5589.

Gazzaley AH, Weiland NG, McEwen BS, Morrison JH (1996) Differ- ential regulation of NMDAR1 mRNA and protein by estradiol in the rat hippocampus. J Neurosci 16:6830-6838.

Ghosh A, Shatz CJ (1992) Pathfinding and target selection by developing geniculocortical axons. J Neurosci 12:39-55.

Gu Q, Bear MF, Singer W (1989) Blockade of NMDA-receptors prevents ocularity changes in kitten visual cortex after reversed monocular deprivation. Dev Brain Res 47:281-288.

Hahm J-O, Langdon RB, Sur M (1991) Disruption of retinogeniculate afferent segregation by antagonists to NMDA receptors. Nature 351:568-570.

Hubel DH, Wiesel TN, LeVay S (1977) Plasticity of ocular dominance columns in monkey striate cortex. Philos Trans R Soc Lond [Biol] 278:377-409.

Isaac JT, Crair MC, Nicoll RA, Malenka RC (1997) Silent synapses during development of thalamocortical inputs. Neuron 18:269-280.

Iwasato T, Erzurumlu RS, Chen DF, Huerta PT, Sasaoka T, Ulupinar E, Tonegawa S (1997) NMDA receptor dependent refinement of body maps in the somatosensory systems. Soc Neurosci Abstr 23:74.

Jackson CA, Peduzzi JD, Hickey TL (1989) Visual cortex development in the ferret. I. Genesis and migration of visual cortical neurons. J Neurosci 9:1242-1253.

Katz LC, Shatz CJ (1996) Synaptic activity and the construction of cortical circuits. Science 274:1133-1138.

Kirkwood A, Bear M (1994) Hebbian synapses in visual cortex. J Neurosci 14:1634-1645.

Kleinschmidt A, Bear M, Singer W (1987) Blockade of "NMDA" receptors disrupts experience-dependent plasticity of kitten striate cortex. Science 238:355.

Komatsu Y, Fuji K, Maeda J, Sakaguchi H, Toyama K (1988) Long-term potentiation of synaptic transmission in kitten visual cortex. J Neurophysiol 59:124-141.

Kopke AKE, Bonk I, Sydow S, Menke H, Spiess J (1993) Characterization of the NR1, NR2A and NR2C receptor proteins. Protein Sci 2:2066-2076.

LeVay S, Stryker MP, Shatz CJ (1978) Ocular dominance columns and their development in layer IV of the cat's visual cortex: a quantitative study. J Comp Neurol 179:223-244.

Li Y, Erzurumlu RS, Chen C, Jhaveri S, Tonegawa S (1994) Whiskerrelated neuronal patterns fail to develop in the trigeminal brainstem nuclei of NMDAR1 knockout mice. Cell 76:427-437.

Luskin MB, Shatz CJ (1985a) Cogeneration of subplate and marginal zone cells in the cat's primary visual cortex. J Neurosci 5:1062-1075.

Mastronarde DN (1989) Correlated firing of retinal ganglion cells. Trends Neurosci 12:75-80.

Meister M, Wong ROL, Baylor DA, Shatz CJ (1991) Synchronous bursts of action potentials in ganglion cells of the developing mammalian retina. Science 252:939-943.

Monyer H, Sprengel R, Schoepfer R, Herb A, Higuchi M, Lomeli H, Burnashev N, Sakmann B, Seeburg PH (1992) Heteromeric NMDA receptors: molecular and functional distinction of subtypes. Science 256:1217-1221.

Moriyoshi K, Masu M, Ishii T, Shigemoto R, Mizuno N, Nakanishi S (1991) Molecular cloning and characterization of the rat NMDA receptor. Nature 354:31-37.

Mower GD, Caplan CJ, Christen WG, Duffy FH (1985) Dark rearing prolongs physiological but not anatomical plasticity of the cat visual cortex. J Comp Neurol 235:448-466.

Murphy KM, Jones DG, Van Sluyters RC (1995) Cytochrome-oxidase blobs in cat primary visual cortex. J Neurosci 15:4196-4208.

Murphy KM, Trepel C, Pegado VD (1996) Non-uniform distribution of the NMDAR1 receptor subunit in kitten visual cortex at the peak of the critical period. Mol Vision 2:9.

Nakanishi S (1992) Molecular diversity of glutamate receptors and implications for brain function. Science 258:579-603.

Perkins AT, Teyler TJ (1988) A critical period for long-term potentiation in the developing rat visual cortex. Brain Res 439:222-229.

Roche KW, Tingley WG, Huganir RL (1994) Glutamate receptor phosphorylation and synaptic plasticity. Curr Opin Neurobiol 4:383-388.

Ruthazer ES, Stryker MP (1996) The role of activity in the development of long-range horizontal connections in area 17 of the ferret. J Neurosci 16:7253-7269.

Ruthazer ES, Baker GE, Stryker MP (1995) Development and pattern of ocular dominance columns in ferret visual cortex. Soc Neurosci Abstr 21:1795.

Schlaggar BL, Fox K, O'Leary DDM (1993) Postsynaptic control of plasticity in developing somatosensory cortex. Nature 364:623-626. 
Shatz CJ, Stryker MP (1978) Ocular dominance in layer IV of the cat's visual cortex and the effects of monocular deprivation. J Physiol (Lond) 281:267-283.

Shatz CJ, Lindstrom SH, Wiesel TN (1977) The distribution of afferents representing the right and left eyes in the cat's visual cortex. Brain Res 131:103-116.

Sheng M, Cummings J, Roldan LA, Jan YN, Jan LY (1994) Changing subunit composition of heteromeric NMDA receptors during development of rat cortex. Nature 368:144-147.

Smith AL, Thompson ID (1994) Distinct laminar differences in the distribution of excitatory amino acid receptors in adult ferret primary visual cortex. Neuroscience 61:467-479.

Stryker MP, Harris WA (1986) Binocular impulse blockade prevents the formation of ocular dominance columns in cat visual cortex. J Neurosci 6:2117-2133.

Sucher NJ, Brose N, Deitcher DL, Awobuluyi M, Gasic G, Bading H, Cepko C, Greenburg M, Jahn J, Heinemann S (1993) Expression of endogenous NMDAR1 transcripts without receptor protein suggests post-transcriptional control in PC12 cells. J Biol Chem 268:22299-22304.
Swindale NV (1988) Role of visual experience in promoting segregation of eye dominance patches in the visual cortex of the cat. J Comp Neurol 267:472-488.

Tingley WG, Ehlers MD, Kameyama K, Doherty D, Ptak JB, Riley CT, Huganir RL (1997) Characterization of protein kinase A and protein kinase C phosphorylation of the $N$-methyl-D-aspartate receptor NR1 subunit using phosphorylation site-specific antibodies. J Biol Chem 272:5157-5166.

Tsumoto T, Hagihara K, Sato H, Hata Y (1987) NMDA receptors in the visual cortex of young kittens are more effective than those of adult cats. Nature 327:513-514.

Wong ROL, Meister M, Shatz CJ (1993) Transient period of correlated bursting activity during development of the mammalian retina. Neuron 11:923-938.

Wong ROL, Chernjavsky A, Smith SJ, Shatz CJ (1995) Early functional neural networks in the developing retina. Nature 374:716-718.

Wong-Riley M (1979) Changes in the visual system of monocularly sutured or enucleated cats demonstrable with cytochrome oxidase histochemistry. Brain Res 171:11-28. 